\title{
Global Health Security Innovation
}

\author{
James Stikeleather and Anthony J. Masys
}

\section{Introduction}

Recent infectious disease outbreaks have demonstrated that a local threat can rapidly become a global crisis that jeopardizes the health, economy, and safety of persons everywhere. For example, the outbreak of severe acute respiratory syndrome in 2003 highlighted vulnerabilities within the global public health community about deficiencies in rapidly detecting and responding to cross border outbreaks, thereby emphasizing that the world was still ill-prepared for global public health emergencies.

'Unexpected events often audit our resilience' everything that was left unprepared becomes a complex problem, and every weakness comes rushing to the forefront' [1]

Challenges in managing the complex landscape of emerging microbial threats, such as cholera, Middle East respiratory syndrome coronavirus (MERS-CoV), Zika in 2015, Ebola (2014-2018) are manifest. With such recent 'disaster events', health security has emerged as a non-traditional security issue affecting national security and global security. The transborder nature of such disease outbreaks as Ebola, H1N1, H5N1, MERS, has emphasized the critical importance of understanding the complexity and resident vulnerabilities that pervade societies with regards to infectious disease threats. These outbreaks, with their transborder character, have resulted in significant global societal and economic impacts. For example, the Ebola epidemic of 2014 affected the West African countries of Liberia, Sierra Leone, and Guinea highlighting the risks of emerging pathogens on global populations. More than 28,000 Ebola cases were reported from the three countries during the epidemic, and $>11,000$ persons died. These countries are among the least developed in the

\footnotetext{
J. Stikeleather · A. J. Masys ( $\square)$

College of Public Health, University of South Florida, Tampa, FL, USA

e-mail: tmasys@health.usf.edu
} 
world, and their weak infrastructures and underfunded health systems were further compromised by the epidemic.

The scope of the impact of pandemics on society is significant. As described in [2:1], the deadliest pandemics in recorded human history include the Black Death pandemic (bubonic/pneumonic plague; 25-40 million deaths) in the fourteenth century; 1918 influenza pandemic (50 million deaths), and the HIV/AIDS pandemic (35 million deaths so far). More recently '. . . cholera has repeatedly reemerged over more than two centuries in association with global travel, changing seasons, war, natural disasters and conditions that lead to inadequate sanitation, poverty and social disruption' [2:2].

The global health security domain is not limited to infectious diseases but has seen the global implication of non-communicable diseases on societies realized in healthcare costs associated rates of heart disease, diabetes, obesity, hypertension, and other non-communicable diseases [3:1886]. In fact, non-communicable diseases are the leading cause of death and disability worldwide. The 'wicked nature' of communicable and non-communicable diseases, drug resistant diseases, emerging and re-emerging diseases highlight gaps in Global Health Security pertaining to preparedness, detection, response. The question becomes, how do we innovate in real-time to manage the global health security landscape.

\section{Complex Problem Framing}

The global health security landscape has an inherent 'wickedness' [4] to it, emerging from a dynamic complexity. Such 'wickedness' or messes are seemingly intractable and are characterized as value-laden, ambiguous and unstable, that resist being tamed by classical problem solving. Actions and interventions associated with this complex problem space can have highly unpredictable and unintended consequences' [5]. Helbing [6] argues that we have '...created pathways along which dangerous and damaging events can spread rapidly and globally'. The World Economic Forum Global Risks [7] places the spread of infectious diseases within the top 10 risks in terms of impact. The risks that pervade our hyper connected world highlight the '...fragility and vulnerabilities that lie within the social/technological/ economic/political/ecological interdependent systems' [8]. This certainly challenges linear, reductionist approaches to problem framing and solution navigation. Woods [9:316] ask the question:

How do people detect that problems are emerging or changing when information is subtle, fragmented, incomplete or distributed across different groups ... Many studies have shown how decision makers in evolving situations can get stuck in a single problem frame and miss or misinterpret new information that should force re-evaluation and revision of the situation assessment....

Recognizing the wickedness of global health security landscape requires a framework and approach to understanding the dynamics, inherent conflicts and possible outcomes resulting from a particular framing of the problem space. 


\section{Discussion}

Crisis management has dominated the Global Health Security domain. Sagan [10:13] argues that 'Things that have never happened before, happen all the time'. This resonates with the problem space of Global Health Security whereby we are continually 'surprised' by epidemic events.

The 'perfect storm' associated with the Ebola outbreak revealed that the governance of global health security is not working. Ebola is just one of many recently emerged zoonotic diseases that have impacted global health security. As described in Belay et al. [11:S65] 75\% of emerging infectious organisms pathogenic to humans are zoonotic in origin and have exhibited cross border transmission resulting in high morbidity and mortality rates. In addition to the high costs in lives, the World Bank estimated that six major zoonotic disease epidemics during 1997-2009 resulted in an economic loss of $>\$ 80$ billion.

The success in eradicating and controlling of infectious diseases is manifest. However much of the dynamic complexity arises from the nature of pathogenic microorganisms that can undergo rapid genetic changes, leading to new phenotypic properties that take advantage of changing host and environmental opportunities. The novel MERS coronavirus in Saudi Arabia, and H7N9 avian influenza virus Eastern China, have pandemic potential with high mortality rates. Events like the Ebola crisis has brought the issue of global health security back on the political and the technical agenda recognizing its societal, political and economic dimensions [12:3].

Moore and Westley [13] argue that 'complex challenges demand complex solutions. By their very nature, these problems are difficult to define'. As described in Masys [5, 14-16] the complexity lens is a key approach to examine and develop new strategic possibilities regarding global health security problem framing that leverages new ways of thinking and innovation. As described in Masys [5], in this complex problem landscape associated with global health security, systems thinking provides a worldview that informs one's understanding and can be used as an approach in problem solving. 'Systems thinking' as discussed in Senge [17] emphasizes interconnectedness, causal complexity and the relation of parts to the whole, thereby challenging traditional linear thinking and simple causal explanations. Senge [17] describes systems thinking as 'a discipline for seeing wholes. . . a framework for seeing interrelationships rather than things, for seeing patterns of change rather than static snapshots'. Systems thinking purports that, although events and objects may appear distinct and separate in space and time, they are all interconnected.

As described in Westley, Zimmerman and Patton [18] '...when we think of a problem as complex, rather than complicated, the inquiry process unfolds in a radically different way. The starting assumption is that of transformation, where true novelty is possible. The status quo needs to be understood, but it is not perceived as a constraint. Resources are assumed to consist of not only what is already part of the system, but that which can be understood or created in relationship to each other'. 


\subsection{Cynefin Framework}

The Cynefin Framework [19-21] is best construed as a sense making tool. In this way it helps us understand that the systems we are engaged in (Global Health Security context) have an inherent dynamic complexity.

The framework (Fig. 1) has five domains divided amongst two overarching characterizations: 'ordered' and 'unordered'. The ordered characterization is comprised of 'simple' and 'complicated' domains whereas the disordered characterization is comprised of 'complex' and 'chaos'. The central domain is that of 'disorder'.

When viewing the global health security landscape, the domain that best supports the problem framing is the complex domain. In this 'un-ordered' domain, there are cause/ effect relationships but their non-linear nature and the multiplicity of agents defy conventional analysis. Considering the outbreaks of H1N1, H5N1, SARS, Ebola, the complex disaster aetiology arises from the intersection of the pathogens with society. When applied to GHS domain, Cynefin points to the complexity that characterizes the problem space thereby leading to the requirement for innovation and creativity as a solution space.

We can't solve problems by using the same kind of thinking we used when we created them. Albert Einstein

Fig. 1 Cynefin Framework. (Kurtz and Snowden [19]. https://doi-org. ezproxy.lib.usf.edu/10. 1147/sj.423.0462)

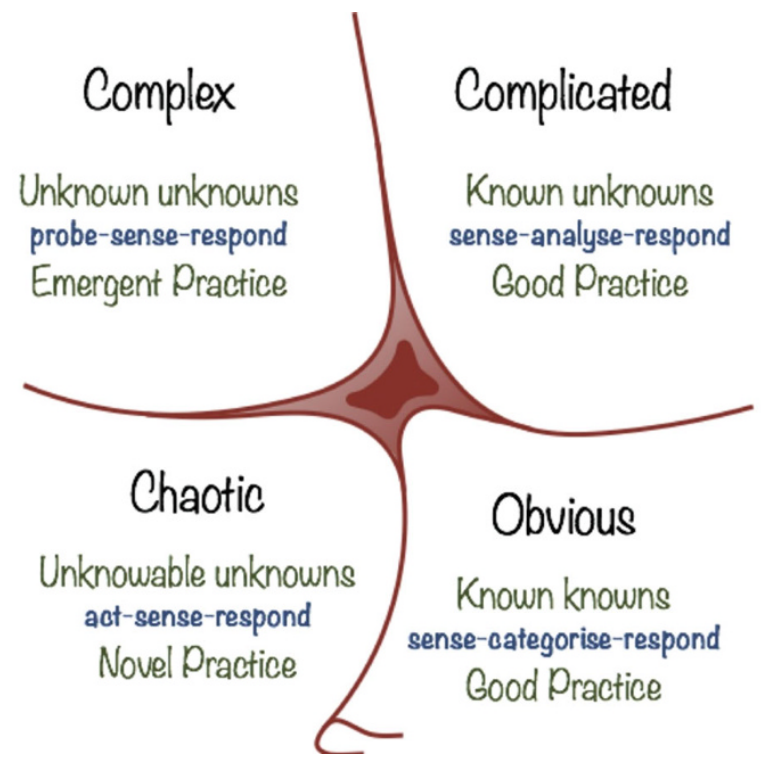




\section{Global Health Security and Innovation}

Managing a wicked problem space such as global health security requires creating conditions and opportunities for innovation.

Innovation is an "essentially contested concept". Gallie [22] originally introduced the term to categorize the sorts of abstract, qualitative, and evaluative concepts such as beauty, fairness, security and social justice in which there are genuine disputes which appear intractable with various uses and criteria of the concept in conflict. Everyone agrees to the concept because it is the only term used, but they cannot agree to its definition, as it is used differently with different interpretations when it is used. For example, a group of people can look at a painting on a wall, agree that it is a painting, further agree that it is a watercolor and not an oil, but might argue vehemently as to whether it was art or not. Innovation, in the vernacular, is the same thing, something that like beauty is in the eye of the beholder.

The Innovation Group at Dell, Inc. developed a set of set of attributes of innovations to address this issue and were useful in making management and investment decisions around potential innovative projects. These are:

- Innovation and invention are different. Invention is the process of taking capital ${ }^{1}$ and creating knowledge. Innovation is the process of taking that knowledge and turning it back into capital by developing a value proposition for stakeholders ${ }^{2}$ using that new knowledge.

- Innovations are new ideas as explained in Everett Rogers' Diffusion of Innovations [25] and defined as a "new idea, creative thoughts, new imaginations in form of device or method", 3 to which the idea of a value proposition is added. An innovation does not have to be a completely new idea but can be an old idea applied in a new way or in a new area. For example, using lessons learned and principles developed in manufacturing and applying them to healthcare.

- An innovation is generally forward thinking, addressing opportunities or problems not yet fully formed or expected in the future. They often surface unrecognized needs or wants. Addressing existing problems in traditional ways, or using Cynefin terminology, addressing simple (with knowns) or complicated (with known unknowns) systems, is the domain of Total Quality Management (TQM), Six Sigma, and other analytic approaches. Innovation applies in potentially changing or replacing those types of systems but is more commonly applied in complex environment (unknown unknowns as a system "probe") or chaotic environments (unknowable as an action).

\footnotetext{
${ }^{1}$ Capital is used here to mean any resource applied which could include funds, people, intellectual property, time, facilities, and even social capital such as reputation and favor exchange.

${ }^{2}$ Any person, group, or "thing" (such as the environment and Dell's innovations around the circular economy) that has an interest or concern (can affect or be affected by) the innovation. The concepts are based upon Freeman's Stakeholder Theory [23] and Samantha Miles' definition and taxonomy [24]

${ }^{3}$ Merriam-webster.com
} 
- An innovation must be feasible, that is it can be made manifest. For example, when the TV series Star Trek ${ }^{4}$ was first aired in 1966 it exhibited two "innovations", the communicator and the transporter. While farfetched in 1966, the communicator was feasible and today most of us carry one around. In fact, Capt. Kirk was limited to using his to ask Scotty to "beam me up", Spock to inquire on the ships computer, Sulu as to where were the Klingons, and McCoy if the red shirt died yet. Our communicators not only allow us to communicate with each other, but have access to the knowledge of humanity, can tell us where we are and how to get to where we want to get to, and a myriad of other things. In fact, we have the entire non-weapons capabilities of the Enterprise in our hands. This is an example of Amara's Law ${ }^{5}$ in action. However, no transporters (technically teleporters) exist nor are they likely (baring a fundamental change in the physics of the universe). They transform mass into information and energy to be reconstructed as mass somewhere else. Einstein's famous equation $\mathrm{E}=\mathrm{mc}^{2}$ suggests this is not very feasible. The bomb that was dropped on Hiroshima in WWII only converted seven tenths of a gram (less than a dollar bill) of material into energy. Imagine what converting a 90,718.5-gram person (200 lbs) to energy would be like?

- An innovation must be viable. In the computer industry there is this concept of SMOP (Small Matter of Programming), which is short hand for many things can be done once if you put in the effort. But once is not viable or sustainable, you must be able to deliver an innovation with repeatability, reliability, and regularly. If you cannot consistently deliver your innovation and its value proposition to its stakeholders, then it really isn't an innovation but a special event (or one off). As part of viability/sustainability is that the value delivered by the innovation must eventually exceed the resources consumed in its creation and other potential uses of those resources (opportunity costs).

- An innovation must be valuable, and it is surprising how often this is missed. Someone or something somewhere must be informed and willing to surrender resources in order to acquire the benefits (value) of the innovation. This was often ignored in the dot com era of the late 1990s, the financial crisis (lack of transparency and information in the "innovative" new financial instruments),

\footnotetext{
${ }^{4}$ Science fiction has an admirable track record in anticipating innovations including television, satellites and "communicators". At Dell, the innovation team was expected to read science fiction. ${ }^{5}$ Roy Charles Amara was an American researcher, scientist, futurist and president of the Institute for the Future best known for coining Amara's law on the effect of technology often applied in foresight and innovation planning. "We tend to overestimate the effect of a technology in the short run and underestimate the effect in the long run."
} 


\section{Forms of Innovation: A Taxonomy}

Innovation is often talked about in terms of new products or services. Many times, products and services are the least valuable forms of innovation and often emerge from the other forms discussed here. In her book Thinking in Systems, Donella Meadows [26] address places to intervene in a system, what she calls leverage points. ${ }^{6}$ Any enterprise, for profit, not for profit, NGO, government, charity, or even a flash mob, all are systems and systems principles (such as Cynefin) apply to them. The forms (taxonomy) of innovation observed in enterprises track well with Meadows' leverage points.

Global Health Security is a nebulous concept that requires a strategic intervention strategy pertaining to innovation. With that in mind, such innnovation must be considered across an enterprise framework to include: products and services, operations, organizational design and management, and business models (Fig. 2).

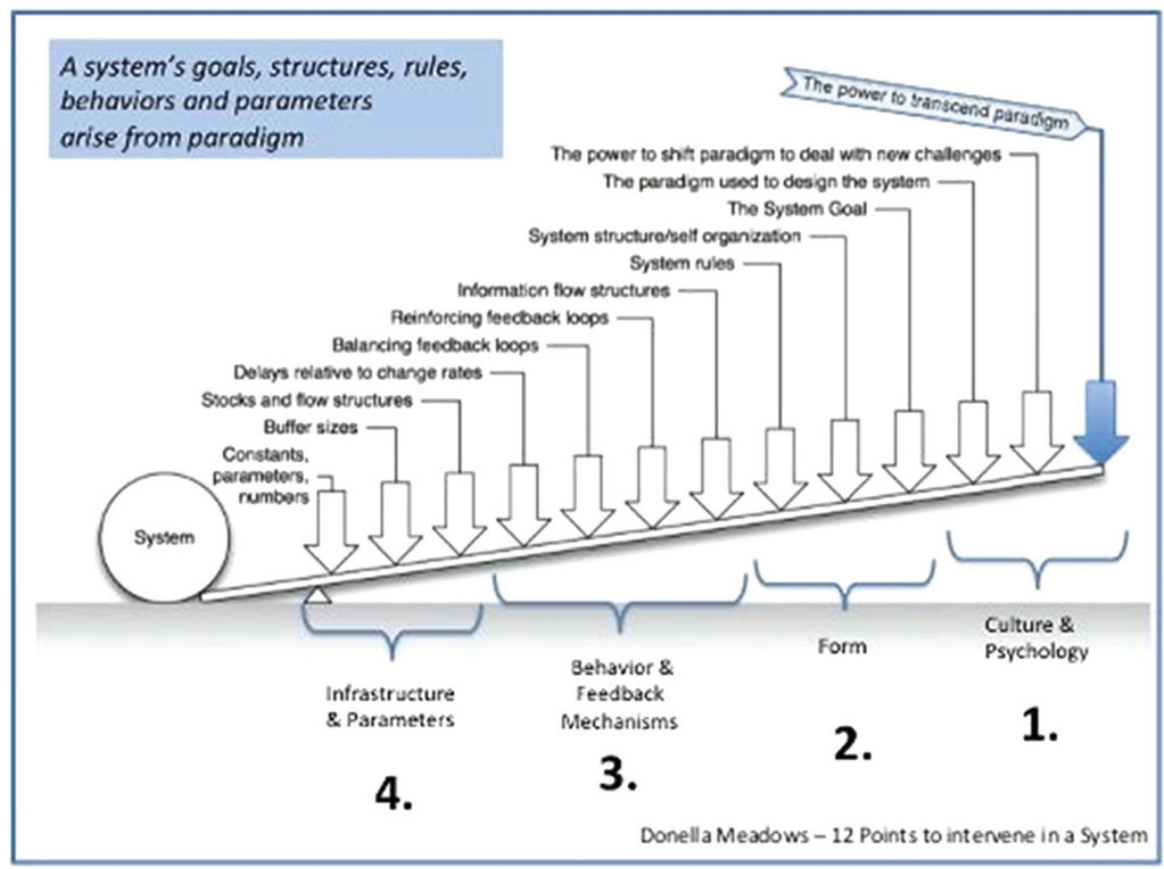

Fig. 2 Points of Leverage in intervening in a system. (Meadows [27]. Thinking in systems: A primer. (Chelsea green publishing)

\footnotetext{
6"Folks who do systems analysis have a great belief in "leverage points." These are places within a complex system (a corporation, an economy, a living body, a city, an ecosystem) where a small shift in one thing can produce big changes in everything."[28]
} 


\subsection{The Products and Services}

Products and services innovation is the most common and best understood form of innovation. It involves creating a new value proposition for stakeholders. It is sometimes incremental innovation where changes in the operating model results in tangible improvements in price, quality, time, flexibility, availability (getting it inventory, delivery), accessibility (getting to it - time, space, financing), functionality, capability, ease of use or other parameters of an existing product or service type. In some cases, the operating model changes are simply part of a continuous improvement process, sometimes they are the result of an innovation in the operating model. This continuous, sustaining, incremental innovation is generally part and parcel of everyday business operations and competition and a result of continuous improvement initiatives such as total quality management (TQM) or six sigma.

Sometimes products and services offer breakthrough innovation wherein an existing stakeholder value proposition is enhanced or changed via an existing product or service but changes in the operating, organizational, managerial or business models resulted in a new stakeholder experience with that product or service. Likewise, a breakthrough innovation can occur with a completely new configuration of products and services based upon the existing higher models but also generating a new stakeholder value experience. Break through innovation is most often both a cause and an effect of industry (enterprises dedicated to a particular value proposition) or market (stakeholders with similar value needs and wants) consolidation.

Disruptive product or service innovations, those which totally reinvent or create new industries or markets are usually the result of innovations at the higher levels of the system. For example, the iPod is often considered a disruptive product innovation, but the reality is that it was a totally new service-based business model, iTunes, that provided the success for the iPod and the eventual disruption of the media industry and the future creation of the smart phone market (and associated industry disruption) via its foundation as an App Store.

From a systems perspective, products and services are the lowest level elements of the system, the most easily changed and, though critical and important, have the least impact on altering the system's (enterprise's) efficient and effective performance of its mission and achievement of its purpose in delivering value to its stakeholders.

\section{The Operating Model}

The operating model is the specific collection of process, organization, location, information, suppliers, technology, and control systems (management) that enables an enterprise to assemble resources and transform them into a value proposition for and delivered to its stakeholders. In systems terms it is the operational model that 


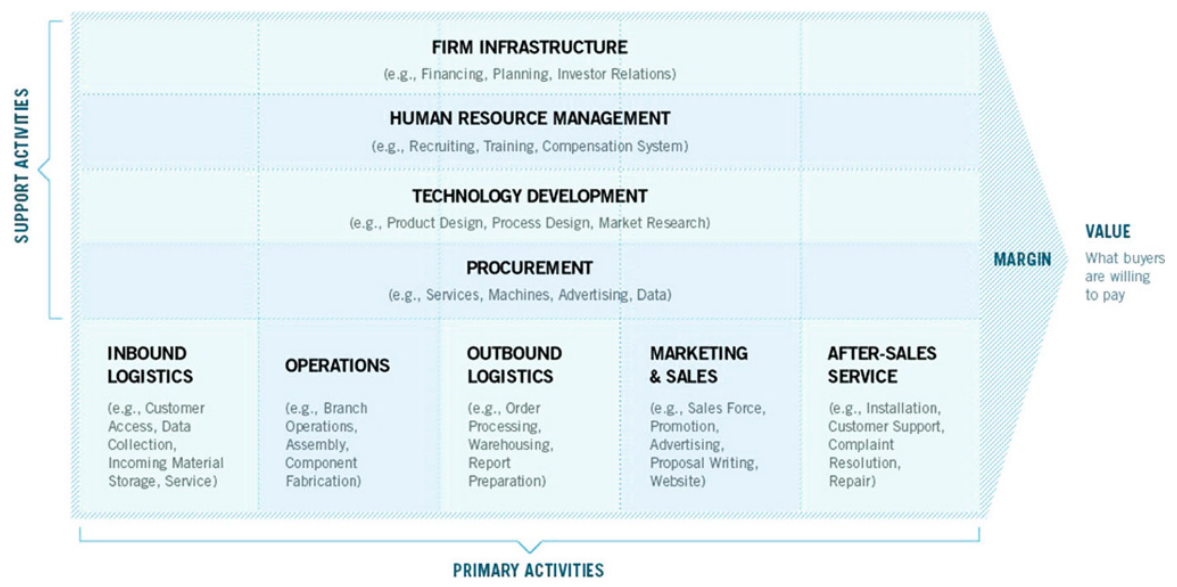

Fig. 3 Porter's value chain model

delivers the behavior (and success or failure) of the system (enterprise). It is composed of processes and procedures using information flow derived from the operations to reinforce its behavior (do more) or balance its behavior (do less or do different) or to delay and potentially stop the value generation process.

An operating model describes the way an enterprise does business today. It is the enterprise's value chain, such as Porter's Value Chain Model [29] made manifest. Innovation at the operating model involves additions, changes, deletions to the information and resource flows across the available capabilities and the associated control structures (Fig. 3).

\subsection{The Organizational and Managerial Models}

The organizational and managerial models provide the form of the enterprise including the structure (What the different parts of the operating model are and how they are put together) to the system (enterprise), clarity and specificity to the goal (mission, purpose, objectives, constraints) of the system (enterprise), the rules the operational level of the system (operational model of the enterprise) must follow, including the rules for changing all of the above.

The organizational model is not just the structure of the organization, but the climates within it and the overall culture. An organizational model defines how activities such as task allocation, coordination and supervision are directed toward the achievement of enterprise goals. The organizational model can enable, facilitate and accelerate the value production of the operating model, or it can severely inhibit it. Innovation is possible in both culture and structure resulting in changes to value delivered to stakeholders. 
"A management model is the choices made by a company's top executives regarding how they define objectives, motivate effort, coordinate activities and allocate resources; in other words, how they define the work of management" [30]. It is the management model that defines the policy and process followed by the operational model as well as how exceptional conditions are to be handled. The managerial model can enable, facilitate and accelerate the value production of the operating model, or it can severely inhibit it. "Over the past 100 years, management innovation, more than any other kind of innovation, has allowed companies to cross new performance thresholds." [31].

Innovation at the managerial model such as Holocracy [32], dynamic teams and project methods such as agile and lean [33], as well as on demand and virtual organizations [34] have resulted in innovations in the delivery of value to stakeholders. $^{7}$

\subsection{The Business Model}

Last, and most significant is the enterprise business model. A business model describes the rationale of why an organization exists and how an organization creates, delivers, and captures value, in economic, social, cultural or other contexts. The process of business model construction and modification is a form of business model innovation and is part of business strategy. While the term business is used here, it applies to any enterprise - public, private, for profit, not for profit, NGO, charity or otherwise who assembles and transforms resources (money, people, time, knowledge, etc.) into value for groups of stakeholders.

There are three areas of innovation available when dealing with an enterprise's business model. First is developing the paradigm of the business. ${ }^{8}$ This includes its vision, mission, and values in the context of the environment within which it operates. Here is a framework for building a business model.

First is establishing the context of the enterprise, how the enterprise wants to participate in that context, its intent on how to accomplish that participation and how to translate that intent in a vision, mission, values, goals, strategies (affirming and constraining) to enable it to take actions to accomplish the outcomes the enterprise seeks (Fig. 4).

These are the (leverage) points of innovation opportunity that can have the most significant impact on the overall system. In Meadows' terms it is a point where the

\footnotetext{
${ }^{7}$ Keep in mind that managers, employees, executives are all stakeholders as well as customers, suppliers, and funders.

${ }^{8} \mathrm{Keep}$ in mind the term business is being used as short hand to describe an assemblage of resources and capabilities to sustainably deliver a value proposition to a group of stakeholders.
} 


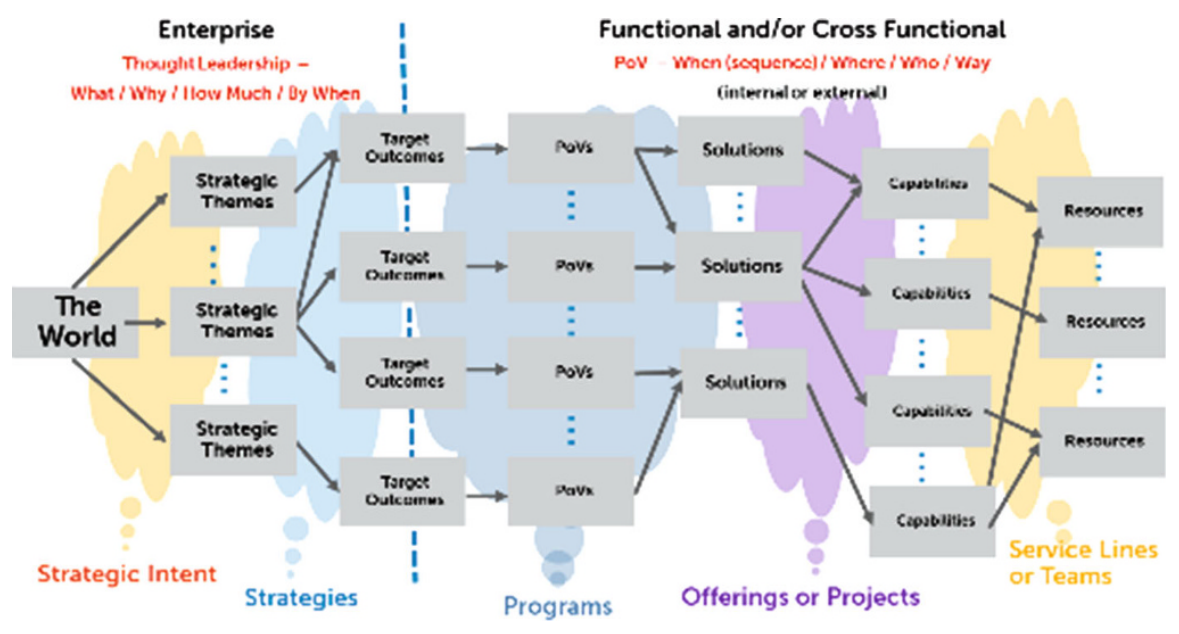

Fig. 4 Strategic planning model developed by the Dell Innovation Team. (Unpublished, Stikeleather 2014)

paradigm of the enterprise is recognized (and could potentially be transcended to something entirely different), it documents the mindset or mental model of the enterprise that engages its stakeholders and drives its activities and establishes the outcomes or goals that define the purpose of and designs the enterprise.

Second, taken to more detail, a framework like the Business Model Canvas of Osterwalder and Pignuer [35] can be used to organize stakeholders, resources, processes into the value creation process. This becomes the foundation for constructing the products and services (value propositions), the operating model on how to construct them, the organizational model for implementing the operating model, and lastly the managerial model for day to day execution and variance control. A Business Model Canvas representation of a business model also provides insights as to where an innovator would want to design, conduct and analyze their MVP/MVS/MVVP experiments described in the next section (Fig. 5).

The third area where the business model offers opportunity for innovation is in the actual design of the enterprise and its relationship with its ecosystem (stakeholders) and environment. It is this designing process, taking advantage of design patterns, system archetypes, and tools such as design research and design thinking that enables opportunities to innovate the managerial, organizational, and operational models of the enterprise for more effective and efficient delivery of value to its stakeholders (Fig. 6).

How to apply these interventions and resulting models are handled in more detail later in the Discussion Section. 


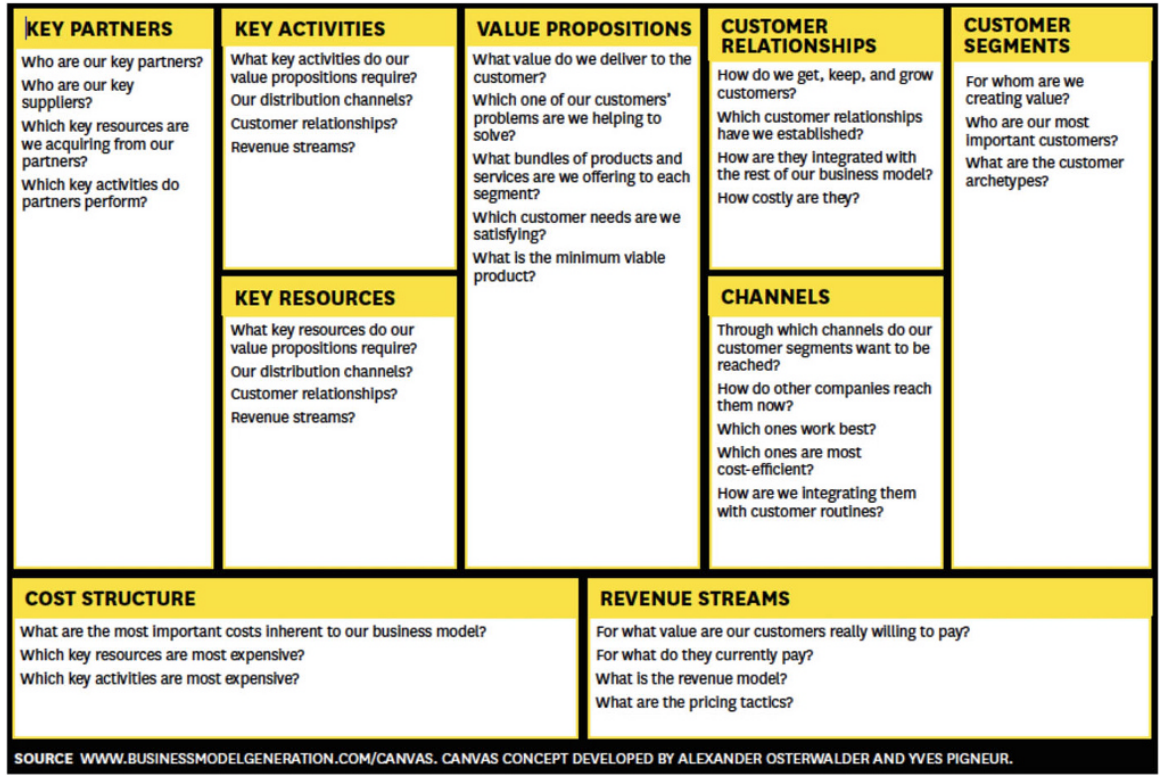

Fig. 5 Business model canvas of Osterwalder and Pignuer [35]

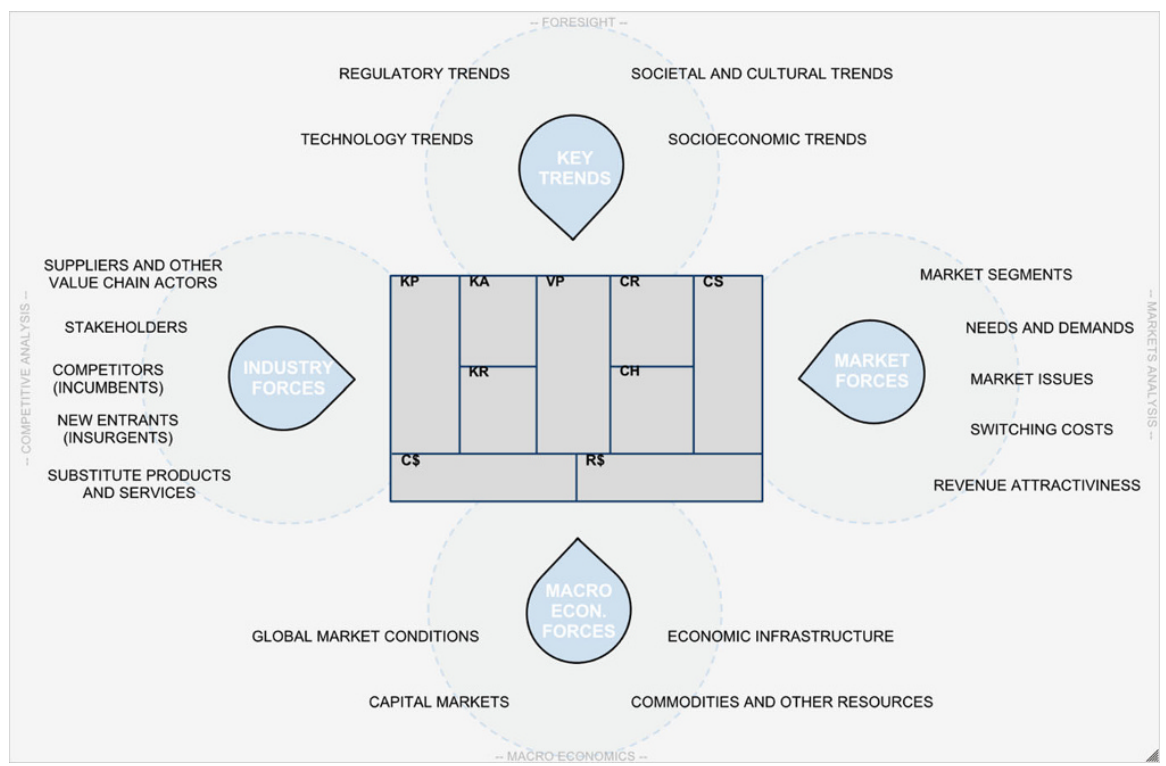

Fig. 6 Business model canvas of Osterwalder and Pignuer with externalities [35] 


\section{Where Does Innovation Come from?}

Innovation is the result of failure. Try something, fail fast, fail furiously, learn, and then try again until you fail into success. Of course, most organizations are not prepared to do this, in fact most organizational structure, policy, and procedure is designed to insure failure does not take place. However innovative enterprises are different. They adopt principles that have come to be called LEAN. Lean thinking and practice help organizations become more innovative and effective, which in turn allows them to become more economically sustainable. Today, lean is considered a new, more effective approach to doing work, no matter what the work is, the sector or the size of the organization. One part of lean focuses on eliminating waste and increasing efficiency (often under the term lean six sigma), which while important, happens after the introduction of the effective innovation.

Earlier, one of the attributes of an innovation was that it was a new idea. Before it is an idea, it is really a hypothesis.

It's important to understand that the words "idea" and "hypotheses" mean two very different things. For most innovators the word "idea" conjures up an insight that immediately requires a plan to bring it to fruition. In contrast, a hypothesis means we have an educated guess that requires experimentation and data to validate or invalidate. ${ }^{9}$

These hypotheses span the gamut from who's the stakeholder(s), to what's the business model, operating model, value proposition (product/service features), pricing, distribution channel, demand creation (customer acquisition, activation, retention, etc.) and any other element of the stakeholder experience (Fig. 7).
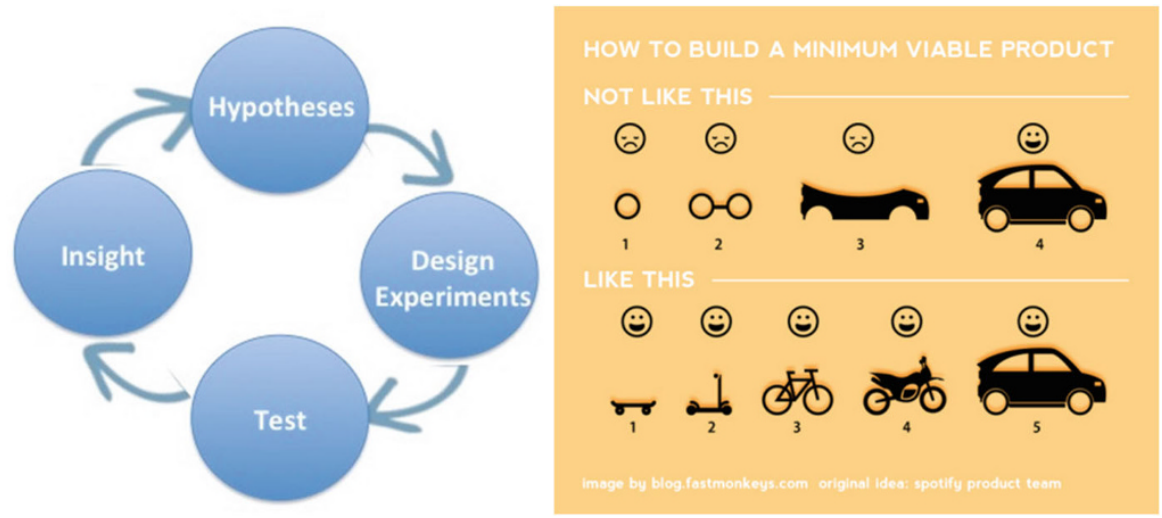

Fig. 7 Developing new product of service, minimal viable approach. (Olsen, D. (2015). The lean product playbook: how to innovate with minimum viable products and rapid customer feedback. Wiley. Retrieved from http://ezproxy.lib.usf.edu/login?url=http://search.ebscohost.com/login. aspx?direct $=$ true $\& \mathrm{db}=$ cat $00847 \mathrm{a} \& \mathrm{AN}=$ usflc.033803999 $\&$ site $=$ eds-live)

\footnotetext{
${ }^{9}$ Why ‘build, Measure, Learn' Isn't Just Throwing Things ... (n.d.). Retrieved from https:// medium.com/startup-grind/why-build-measure-learn-isn-t-just-throwing-thi
} 


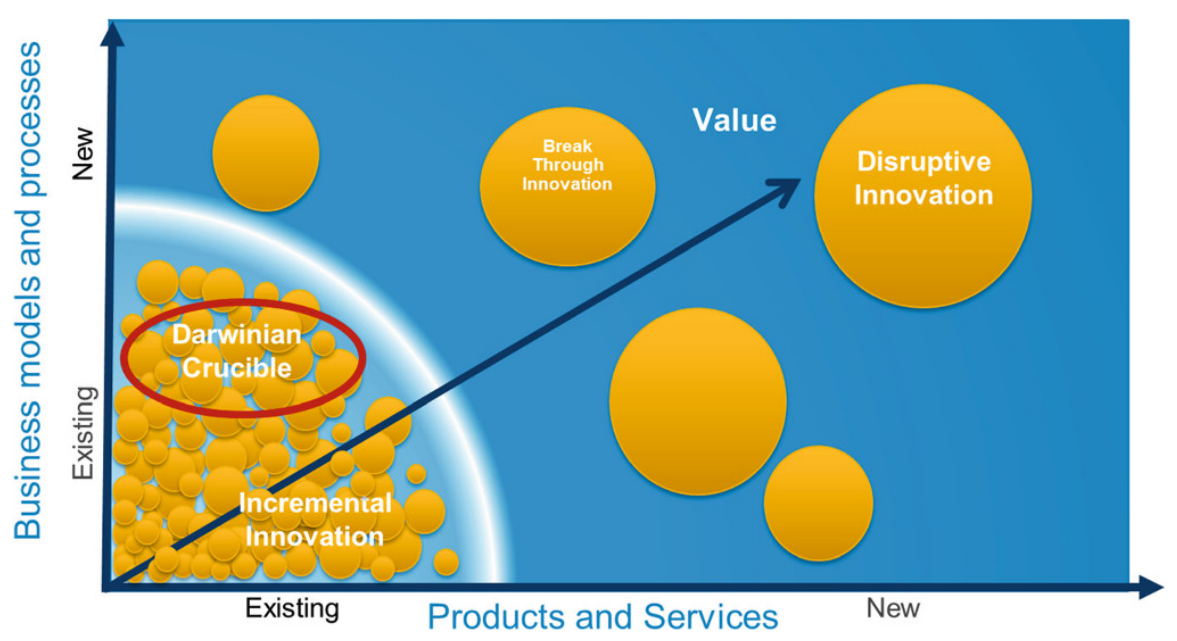

Fig. 8 Innovation portfolio model developed by the Dell Innovation Team. (Unpublished, Stikeleather 2014)

These experiments are equivalent to the "probe" step in addressing a complex system and the "action" step in addressing a chaotic system as described by the Cynefin Framework. Taking these experiments to "market" and observing their (likely) failure provides the insights to refine the hypothesis (improve the idea) and then experiment some more. This is the foundation for the concept "fail fast, fail furiously, learn, and then try again until you fail into success" as the source of innovation. Any potential innovation is simply a collection of untested hypotheses in the beginning (Fig. 8).

Scientists and engineers never test their ideas (hypotheses) at full scale or in totality. If things go wrong (fail) it is hard to determine what part(s) were the sources of the failure. Instead they create small scale or partial tests of their ideas. When talking about delivering value to a stakeholder or stakeholders, this is referred to as building a minimal viable product or service. The goal of an MVP or MVS is to provide enough value (Minimum Viable Value Proposition - worth the stakeholder's effort to engage) that the stakeholders can legitimately evaluate some element of the offering, the innovator can legitimately evaluate the need infrastructure and ecosystem of resources and capabilities to evaluate and project resource consumption to deliver the value to the stakeholders, and do so with the least possible consumption of resources but sufficient to have an informative experiment. What the innovator is trying to establish with these series of experiments, tests, insights, and revisions to the idea (hypothesis) is to establish the total value proposition to all stakeholders, including themselves (see below, not necessarily exhaustive list).

Keep in mind that these MVP/MVS/MVVP experiments are meant to gain insight for all of the models referenced in the Innovation Taxonomy, not just the offering to the stakeholders. 


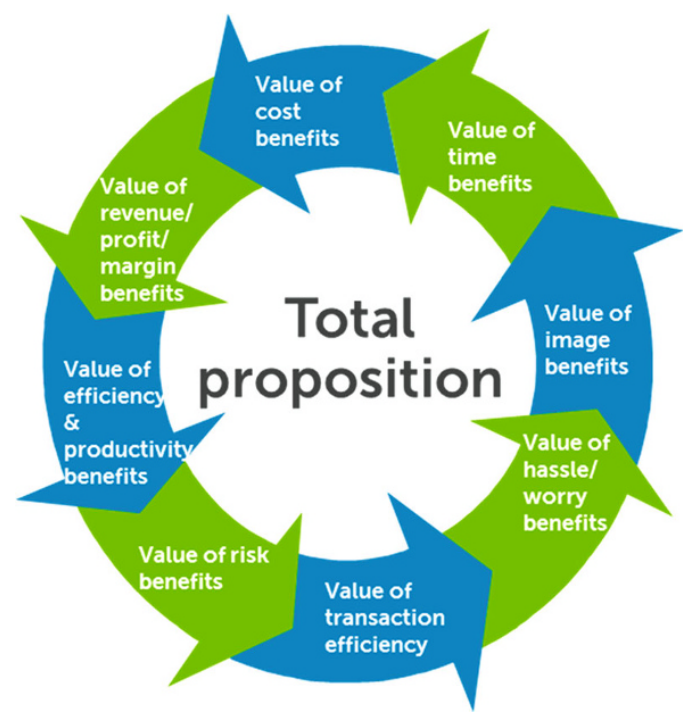

\section{How Do You Enable, Facilitate and Accelerate It?}

Innovation is an emergent activity. It can be planned, though anticipated is perhaps a better term, through foresight and future study in order to concentrate the enterprise's attention on high probability or high reward opportunities. Having the right types of people is important. They have to be found, but in the right environment people can acquire and develop the necessary skills even if they do not have them to begin with.

That is the real key, having the right environment of processes, leadership, rewards and a common language of what is meant by innovation and how to go about it.

\subsection{Right People}

There is a misconception about how innovation occurs. It is often thought that innovation comes from the brilliant lone wolf idea guy when in reality innovation is a team sport. There are always at least three personas associated with innovation. Perhaps they can all reside in one person, but more than likely they are spread across a whole team of people. 
First is the idea generator(s) who see the future through foresight and future study, who sees the jobs that stakeholders are trying to accomplish and the value that can accrue to them if the job is accomplished. Idea generators see the environment, the opportunities, the challenges and construct a strategy and team for dealing with them. The classic example is Steve Jobs who saw the potential of a personal computer for individuals who were not nerds capable of building one for themselves.

But the best idea however is worthless unless it can be made real. This is the realm of the idea manifestors. They take that collection of value propositions from the idea generators and apply technologies, processes, resources, organizations in such a way that a product or service becomes real and can be delivered to the stakeholders who will benefit from it. Manifesting is not just producing a product or service but the business model, management model, organizational model, and operating model that produces the product or service. Continuing the Apple analogy, the manifestor in chief was the Woz.

Even the best product or service cannot deliver value unless the stakeholders whom it could benefit or from whom it could take contributions know about it. This is where the idea communicators bring their skills to bear. It is one thing for the idea originator and manifestor to understand the value of a product or service (or the system that creates and delivers it). But often times they understand it in ways differently than other stakeholders would. It is the job of the idea communicator to translate the values, features, functions, capabilities, benefits of the offering into concepts and terminology stakeholders can understand and use to make informed decisions about the offering. To finish the Apple analogy, this would have been Regis McKenna. ${ }^{10}$

All innovations are born from the parenting of these three personas. These personas also have personalities, things that enables innovation to thrive around them. First, they do not quite fit the existing models (business, management, organizational, operating) as they think and act out of the box. In terms of the emergent organization of the enterprise, they are likely outsiders because they see things differently or have different interests. They are probably infected with the 5-year old's disease, constantly asking why things are the way they are, why they are done the way they are done. They are constantly networking inside and outside the organization, generally outside of organization and industry boundaries. They are also keen observers, the source of the infinite number of "whys" and are always trying things out or experimenting.

\subsection{Right Process}

Scott Anthony in The Little Black Book of Innovation [36] talks about the process of innovation as it emerges in organizations and some of the commonalities in

\footnotetext{
${ }^{10}$ https://en.wikipedia.org/wiki/Regis_McKenna
} 
innovative organizations. He talks about discovering opportunities, effectively the discussion on foresight and future study. He talks about blueprinting ideas such as Minimal Viable Products, Minimal Viable Services, and Minimally Viable Value Propositions that can then allow the testing of the ideas (hypothesis) with the least risk and maximal learning opportunities. Lastly, he talks about moving forward, which is progressive executions of these ideas until they succeed as products, services, value propositions, and the enterprises and ecosystems necessary for them to exist.

A mental model based upon a systems approach to innovation [37] with the right processes, linked with the right leadership behavior discussed below, establishes and nurtures the environment wherein innovation grows and thrives. For example, have policies and processes that encourage and reward failure where valuable learning takes place, yet recognizes the eventual goal of success. Having policies and processes that support and reward creativity rather than standardization and automation yet recognize efficiency and efficacy. Having policies and processes that provide for and encourage "idle" time as that where creativity and divergent thinking takes place, yet keeps focus on the goal and urgency to create value for stakeholders.

In other words, an environment of leadership rather than management and supervision.

\subsection{Leadership Role Modeling}

Ram Charan in his book The Game Changer [38] talks about one does not lead so much as one demonstrates leadership. There are five key elements to leading innovation activities:

- Shaping Context. The role of an innovation leader is not to tell people what to do or how to do it. Instead it is to communicate the desired outcome such as making a wicked problem less troublesome or making the "victims" of a wicked problem a little better. It is also important that the leader establish the limits on the inputs and processes, the constraints on the innovation around its characteristics (new, forward thinking, feasible, viable, and valuable) so that the innovators may measure their progress. It is not only telling the innovators, but demonstrating it to them with the leasers own decisions and actions.

- Actively participating. Innovation is not a steering committee exercise. The innovation leader is one of the innovators actively engaged in the innovation process and work with the team.

- Engaged review. Innovation reviews should never be status dumps. They should be truly informative and engage debates on issues, opportunities to improve, changes in constraints, etc., involving the leader and an innovation team peer.

- Process breaking. A typical managerial role is to enforce process, standards and limit variability. An innovation leader's role is the exact opposite. Seeking innovation is a de facto admission that current policy and process is not effective 
or efficient in addressing the problem or opportunity at hand. However organizations are designed around "make no mistakes", have no excess capacity, ensure conformance and other dictums that are the antithesis of innovation. The role of the leader is to cut through all those "good for production efficiency and risk reduction" rules, policy and process to enable incurring risk, increasing variability, and facilitate learning failure.

- Being available. Innovation and addressing wicked problems is an ego bruising, if not busting, exercise in ongoing futility, with success around some distant corner. The leader must motivate the team through this (see next section) but importantly, must be always available to help the team celebrate success, deal with failure, and recognize and appreciate the difference.

\subsection{Right Rewards and Incentives}

Daniel Pink in his work Drive ${ }^{11}$ the surprising truth about what motivates us [39] which is important when consideration innovation. Innovation requires creativity, it requires perseverance to address wicked problems which are never solved only made better or less worse, hopefully. Innovation work is not algorithmic in which the same thing is done repeatedly but is instead heuristic requiring the innovators to come up with new ways to do things continuously with no real instructions to follow other than their mental models. Pink's research and that of others examined traditional rewards and incentives when we want to motivate people to be creative, problems solving and innovative.

Pink shows that extrinsic rewards can be effective for algorithmic tasks-those that depend on following an existing formula to its logical conclusion. But for more right-brain undertakings - those that demand flexible problem-solving, inventiveness, or conceptual understanding such as addressing wicked problems - contingent rewards can be counterproductive causing loss of intrinsic interest for the activity and the ability to persevere in it. Instead, the secret to motivating innovation isn't our traditional biological drives or our reward-and-punishment drive, but our third drive-our deep-seated desire to direct our own lives, to extend and expand our abilities, and to live a life of purpose.

For fostering innovation in the addressing of wicked problems, a new approach to motivation has three essential elements:

- Autonomy, the desire to direct our own lives;

- Mastery, the urge to get better and better at something that matters; and

- Purpose, the yearning to do what we do in the service of something larger than ourselves.

\footnotetext{
${ }^{11}$ A short but comprehensive video of "Drive" can be found here - https://www.youtube.com/ watch? $\mathrm{v}=\mathrm{u} 6 \mathrm{XAPnuFjJc}$
} 


\subsection{Common Language}

A common language is really just a shared mental model of what innovation is, how to go about it, and why you are going about it. It is a collection of ideas such as the business model canvas, "lean" approaches to testing ideas, that failure is good if something is learned, it is the idea of stakeholders and how the enterprise can create value for them. In the case of innovation, it is a systems thinking approach to value creation across business models, management models, organization models, operating models as well as the end products and services.

It is keeping in mind and using all of the characteristics of innovation (forward thinking, new (or new use of) ideas, feasible, viable and valuable. It is also understanding that innovation is not what the enterprise does, but rather it is what the stakeholders adopt.

Using a common set of mental models for managing innovation is to make sense of a complex, uncertain and highly risky set of phenomena as encountered in complex and chaotic environments as described by Cynefin. Because innovation is messy with many false starts, dead ends, leaps of faith and iterative failures to success, it is the mental models that keep everything on track. This idea is described in detail by Tidd, Bessant and Pavitt [14]. Likewise, a common language about innovation, in particular recognize all potential stakeholders identified in future studies, helps avoid overly focusing on technological opportunities and immediate value creation to include less obvious social concerns, expectations and pressures that make up the wicked problems the innovation is attempting to address.

Mental models are difficult to change and are one of the biggest barriers for innovation as they determine the level of assimilation of new ideas find and the level and quality of effort that will be put into them. The importance of shared mental models among a team cannot be understated as demonstrated by Prasad Kaipa's article "Steve Jobs and the Art of Mental Model Innovation". ${ }^{2}$

It is a common language or shared mental model that keeps innovation on track when dealing with a wicked problem that involves complex systems of disruptive and discontinuous events and networks of actors and sources.

As discussed earlier, a sensemaking framework such as the Cynefin Framework helps us to understand the role of evidence-based practices to work across the simple, complicated and complexity domain and to shed light on the perils of oversimplification. In this way, Cynefin promotes reflective practices [40] that help to shape effective intervention strategies and the pitfalls of unintended consequences. Managing uncertainty within the global health security landscape requires one to explore the possibility/plausibility space to enable innovation. Foresight thereby becomes a key tool to support global health security innovation.

\footnotetext{
${ }^{12} \mathrm{https}$ ://iveybusinessjournal.com/publication/steve-jobs-and-the-art-of-mental-model-innovation/
} 


\section{Using Foresight and Futures Study to Support Innovation}

Prediction is very difficult, especially if it's about the future. Niels Bohr

The concept of using foresight and studying potential futures is a critical component of innovation as discussed previously.

Foresight is the act of looking to and thinking about the future. Foresight enables you to get better at predicting, creating, and leading the future. There is a tiny but growing community of professional futurists, people who think and talk about various aspects of the future full-time. However, anyone can learn efficient and effective tools and methods for envisioning and planning to reach a desirable future.

The foresight and futures study area is very broad, and goes by a variety of different names:

- Futures research,

- Futures analysis

- Futurism

- Futuristics

- Futurology

For many, these have rather negative connotations of respectively sloppy or very superficial work done on behest of commercial marketing activities, or of excessively empiricist and overly-prediction-oriented academic work in specialized fields such as predicting future compute power of chips. The subject of this discussion has nothing whatsoever to do with stock market "futures trading" or speculation. Instead, futurists use the plural of "futures" specifically because the master concept of the foresight and futures field is that of the existence of many potential alternative futures, rather than simply a single future.

Ray Amara, ${ }^{13}$ a former president of the Institute for the Future once suggested [41] that there are three fundamental premises upon which the futures field rests:

- The future is not predetermined. This is actually a direct consequence of understanding that the real world we deal with is either complex or chaotic as described in the Cynefin framework where new futures emerge whose cause can only be seen retrospectively (complex) or are just the consequence of totally random events (chaotic). Therefore, there cannot be any single predetermined future or prediction, but one can construct many potential alternative futures that can be anticipated.

- The future is not predictable. This is actually an extension to the previous premise. Even if the future were predetermined, we could never collect enough

\footnotetext{
${ }^{13}$ Amara is best known for Amara's Law - We tend to overestimate the effect of a technology in the short run and underestimate the effect in the long run.
} 
information about it to a degree of accuracy necessary to construct a complete model of how it would develop. The errors introduced by not having precise information would cause the model to deviate from what is happening in the system we are modeling.

- Future outcomes can be influenced by our choices in the present. We can influence by the shape of the future which does happen by the choices we make regarding our actions (or inaction) in the present (inaction is also a choice). This is the reason anticipating possible futures is important, because from them we can derive current actions that might result in the manifestation of a preferred future.

This ability to take responsibility for our futures is a foundation for creating and managing innovation in all its forms. The actual future which eventuates, and in which we will ultimately live and experience as the present then, will be governed by our actions or inaction now, along with the choices we have made among many alternative potential futures anticipated. We make those choices by altering the course of the present by introducing innovations into our operating models, organization models, management models, business models, the value we create through products and services, and the stakeholder communities we seek to deliver that value.

\subsection{Anticipated Futures}

While it is possible, and fun, to generate an infinite number of potential alternative futures, Henchey [42] proposed four distinguishable classes, later expanded by Voros [43] to five, to help facilitate focusing on those with the highest probability of impact upon the forecaster.

- Possible futures. These are those which "might happen" no matter how ridiculous, unlikely or outside of the box of normal ideas or expectations. These are generally reliant on the existence of some future knowledge or capability do not yet possess and not sure where it might come from (but we can imagine it) in order to come about. Possible futures are imaginative.

- Plausible futures. These could happen. They do not rely upon knowledge or capabilities that do not yet exist, or if they do, there is a reasonably clear path on how that knowledge or capability might emerge. Care needs to be taken here as this is determined by our current understanding of physical laws, processes, causation, systems of human interaction, regulation, and other areas where we may not be fully informed. Because of this, plausible futures should be researched to confirm or expand our understanding of the current state of knowledge and capabilities. These are a subset of the possible futures.

- Probable futures. These are fundamentally continuations of current trends, a business as usual linear extension of the present, and are therefore considered likely to happen. These are usually the extent of most strategic planners' considerations. This is dangerous as few trends are continuous over long periods of time, 


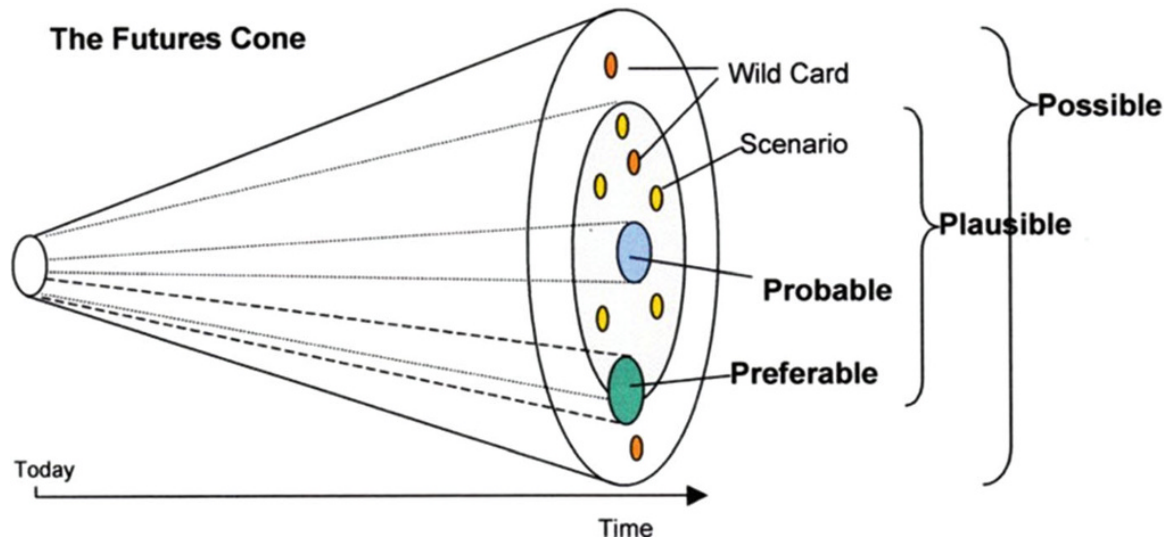

Fig. 9 This image was adapted by Joseph Voros [43] from the work of Hancock and Bezold [45]

and they made fade away suddenly or be usurped suddenly by a new one unexpectedly (unless identified in a possible or plausible future). Simply reading trends, which is what many marketeers and strategist do, is not foresight. The resulting probable futures is a much smaller subset of possible futures that may impact the enterprise and its stakeholders.

- Preferable futures. These represent what we want to have happen. While the previous futures are basically cognitively and generally objectively derived, these involve value judgements and are more subjective. This set of futures can intersect any or the above futures and are not part of a continuous subset progression as the others are.

- Wild card futures. These are low probability futures, or perhaps highly specific futures (reducing their probability for all of the complexity and chaos reasons discussed earlier) but have an additional characteristic that should they occur they would have a very significant outsized impact on our enterprise and/or its stakeholders. These futures are sometimes referred to as black swan events from their description and analysis by Taleb [44] (Fig. 9).

The value of foresight activities is directly related to the depth of work done [63, 64]. The least useful is the "reading trends" approach discussed above. This is the shallowest and most superficial level of futures thinking; it is also by far the most widespread, well-known and popular. It is usually highly media-oriented and is found in television reports, in newspaper magazine articles, popular books, and "sound bites" by "experts". It only reveals a very small segment of the potential futures and is often preoccupied with technology. There is little insight or innovation value found at this level.

A more serious level is often concerned with how organizations and society might, or ought to, respond to challenges lying in the nearer-term future. This is where strategic thinking should take place and, in the public sector, often touches upon the "big-picture" and "wicked" problems as described earlier. This is referred 
to as problem-oriented futures work and is where the majority of effort should and does take place in innovation.

Slaughter goes on to describe "critical futures studies" which is more related to Social Systems Theory [36] dealing with how we create the problems in the first place through our worldviews and unquestioned assumptions. He also describes "epistemological futures work" where futures work integrates with philosophy, epistemology, ontology, cosmology, macro history, the study of time, the nature and influence of consciousness on the human endeavor and other areas of human society. Both of these levels are usually beyond the interest and utility of everyday practitioners of innovation.

This layering of futures thinking has been used by futures researchers to develop analytical methods to get to the issues beneath the all the many wicked problems and themes which tend to capture and divert our attention and keep us from developing innovations that improve the situations we are trying to address. The layering also supports the different approaches to foresight including:

- Pragmatic foresight. This generally looks for opportunities within known problem spaces. This is what is most common in business, where it seeks new markets, new challenges, innovation, is highly entrepreneurial, and looks at the future as an ecological competitive space within which one needs to adapt in order to gain advantage. Innovation here tends to focus on products and services, operating models, and organizational models.

- Progressive foresight. Whereas pragmatic foresight works on innovation among participants within a known ecology or system, progressive foresight looks for ways in which the system or ecology itself can be innovated, transformed and create more value for participants or create new participants. Innovation here looks like what the business press calls "digital transformation" and creates new ecosystems (online retail) and new participants (Amazon). Innovation here tends to center on management models and business models.

- Civilizational foresight. This focuses on potential change to multiple ecosystems in an ecosphere. It is called civilizational as it is often looking at preferable futures of a complete society and what can be done to bring one about. In business this tends to happen outside the enterprise with emerging concepts of corporate social responsibility [55], corporate shared value [47], and the rise of new legal structures such as benefit corporations [48] as examples of resulting innovations.

You can address foresight at four levels:

- Personal - improving our individual, relationship, and family navigation of the future.

- Organizational - improving our teams, companies, and institutions abilities to create the futures they desire.

- Global - improving our societies ability to cooperate, compete and adapt.

- Universal - which includes science, complexity studies, and models for universal change. 
The point of this section is not to teach foresight and future studies but to increase awareness of the discipline, its usefulness in understanding and addressing wicked problems though innovation. Being able to anticipate the potential jobs to be done in the future by the enterprise to provide value to its stakeholders, to understand how to potentially reduce the pains of the stakeholders in accomplishing those jobs as well as increasing the value of the job accomplishments themselves, is the basis of successful innovation. There are many helpful organizations, most non-profit think tanks, that supply education and input for a foresight process. Some of the leading ones are:

- The Institute for the Future - "Making the Future with Foresight - IFTF is celebrating its 50th anniversary as the world's leading non-profit strategic futures organization." http://www.iftf.org/home/

- The Future Society - "Our mission is to help build a future that preserves humanity while harnessing the upsides of technology." http://www. thefuturesociety.org/

- World Future Society - "community of future-minded citizens charting a new course for humanity" https://www.worldfuture.org/

- And smaller, but no less interesting ones such as futurist.comhttps://www.futur ist.com/think-tank/ and the Da Vinci Institute https://www.davinciinstitute.com/

- As well as ones that focus on areas of interest such as Foresight Institute "focusing on molecular machine nanotechnology, cybersecurity, artificial intelligence" https://foresight.org/

There are also university programs:

- Futures Studies and Foresight Education at Finland University - https://www. finlanduniversity.com/service/futures-studies-and-foresight-education/

- University of Houston's Graduate Program in Foresight - http://www.uh.edu/ technology/departments/hdcs/graduate/fore/

- With a fairly complete list available here: https://www.accelerating.org/ gradprograms.html

And there are many very good texts, papers, and sites. A great starting point would be Andy Hines and Peter Bishop's Thinking about the Future: Guidelines for Strategic Foresight [49].

\subsection{A Note of Caution}

Because it involves all the elements of sensemaking [50] and systems thinking such as analysis, synthesis, induction, deduction, abduction, observation and creativity, foresight is subject to many of the weaknesses of human intellectual processes. This is compounded by the fact there is no test for correctness other than time itself. 
Consequentially, self awareness and reflection are critical in foresight and futures research.

Futures researchers must be aware of which thinking system they are using $[51,52]$ and not jump to conclusions based upon their existing, comfortable mental models but entertain new mental models [53].

Good foresight and futures work are based upon what is as opposed to what should be. Incorporating the potential (likelihood) of irrationality on the part of the stakeholders, as well as the futures researchers decision making [54].

Lastly, foresight and futures researchers are encouraged to regularly assess how bias $^{14}$ and logical fallacies ${ }^{15}$ may be entering their research before applying their conclusions into constructing future innovation planning scenarios.

\subsection{Intervening in the Systems of Health Security}

Intervening and innovation in the system associated with Global health security requires the following:

- Recognizing systems and systems thinking

- Mental models and problem framing

- Divergent thinking

- Design and experimentation (real time and foresight)

Returning to Weick and Sutcliffe [1] '... unexpected events often audit our resilience, everything that was left unprepared becomes a complex problem, and every weakness comes rushing to the forefront': the complex threat landscape associated with global health security matters requires a mindset that embraces innovation and creativity. The application of systems thinking, Cynefin and Foresight as toolsets to support innovation presents a method of inquiry that unfolds in a radically different way from traditional linear approaches.

There are a few key concepts to keep in mind when intervening in a system.

\footnotetext{
14“"Cognitive biases make our judgments irrational. We have evolved to use shortcuts in our thinking, which are often useful, but a cognitive bias means there's a kind of misfiring going on causing us to lose objectivity. This website has been designed to help you identify some of the most common biases stuffing up your thinking." https://yourbias.is/

15“A logical fallacy is a flaw in reasoning. Logical fallacies are like tricks or illusions of thought, and they're often very sneakily used by politicians and the media to fool people. Don't be fooled! This website has been designed to help you identify and call out dodgy logic wherever it may raise its ugly, incoherent head." https://yourlogicalfallacyis.com/
} 


\subsection{Recognize You Are Dealing with a System}

Through this chapter we have used the term system assuming a common understanding. It is important to be working from a common understanding of what is meant by a system. An excellent introduction to what a system is and how to think about it can be found at the Systems Thinker web site. ${ }^{16}$ It is beyond the scope of this chapter address all the concepts and issues of the systems paradigm, general systems theory, systems thinking, sensemaking, complexity, systems innovation and other concepts discussed here in more depth. However, there is an excellent collection of articles, instruction, videos for learning a disciplined approach to these topics at Complexity Labs. ${ }^{17}$ Another good source for learning systems thinking is the Waters Foundation. ${ }^{18}$ An excellent review of available resources on the topic is provided by Monat and Gannon [55] which the reader is encouraged to peruse.

By understanding what a system is, it becomes easier to identify what system (or system of another system) you are dealing with at a moment in time, where its boundaries are, and how it is behaving. This is the critical first step in building a mental model or map of the landscape [50] that you want to understand, to intervene in, and to change its behavior. This is called sensemaking and it is "a key leadership capability for the complex and dynamic world we live in today" that enable leaders to "explore the wider system, create a map of that system, and act in the system to learn from it" [56]. It is the process of "the making of sense" [57] of an environment by "structuring the unknown" [58] by observing and structuring the inputs (signals, information, resources, etc.) to the system and the consequential behaviors and outputs as the inputs vary "to comprehend, understand, explain, attribute, extrapolate, and predict" [59] in order to prepare to intervene and measure the effects on an intervention in the system (Fig. 10a).

Systems thinking, approaching problems and asking how various elements within a system, which could be an ecosystem, an organization, or something more dispersed such as a health care system, influence one another, uses an iceberg model to describe the process. Rather than reacting to individual problems that arise, a systems thinker will ask about relationships to other activities within the system, look for patterns over time, and seek root causes.

For more details on the iceberg model, ${ }^{19}$ the reader is encouraged to review Senge, Kleiner, Roberts, Ross, and Smith, " The Fifth Discipline Fieldbook" [60] which is an applied perspective of the background and theory of systems thinking presented in "The Fifth Discipline" [61].

Such an approach is crucial for "wicked problems" [4] such as health security. A wicked problem is a problem that is difficult or impossible to solve for as many as four reasons: incomplete or contradictory knowledge, the number of people and

\footnotetext{
${ }^{16} \mathrm{https}$ ://thesystemsthinker.com/introduction-to-systems-thinking/

${ }^{17} \mathrm{http}: / /$ complexitylabs.io/ (disclosure one of the authors is a member)

${ }^{18} \mathrm{https}$ ://www.watersfoundation.org/

${ }^{19} \mathrm{~A}$ quick introduction is available here: https://nwei.org/iceberg/
} 


\section{Iceberg... Seeing What's Below the Surface}

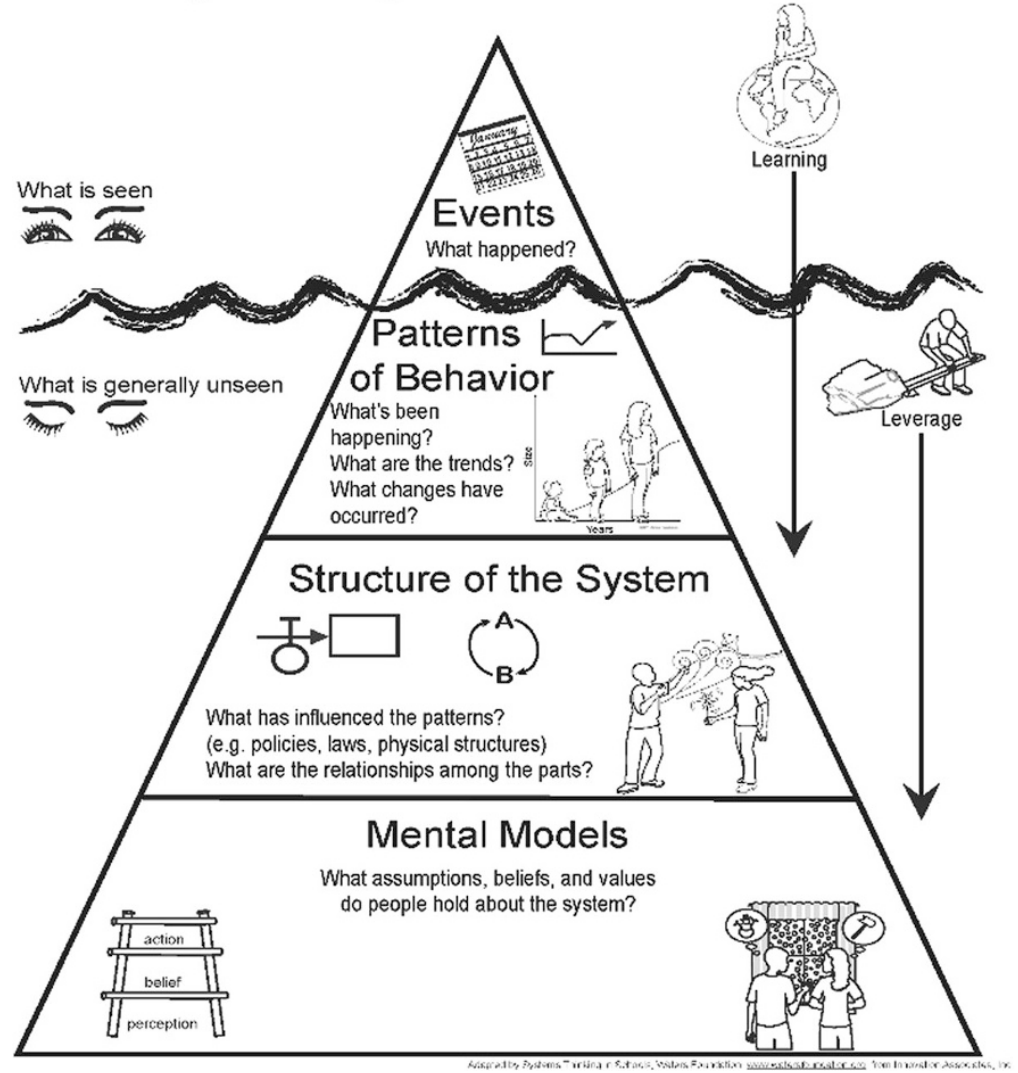

Fig. 10a Adapted from systems thinking in schools, Waters Foundation, www.watersfoundation. org

opinions involved, the large economic burden, and the interconnected nature of these problems with other problems. Almost all social, political, cultural, and organizational problems are "wicked."

According to Rittel, there are ten characteristics of wicked problems, which are crucial to understand before attempting any intervention:

- Wicked problems have no definitive formulation. The problem of poverty in Texas is grossly similar but discretely different from poverty in Nairobi, so no practical characteristics describe "poverty."

- It's hard, maybe impossible, to measure or claim success with wicked problems because they bleed into one another, unlike the boundaries of traditional design problems that can be articulated or defined.

- Solutions to wicked problems can be only good or bad, not true or false. There is no idealized end state to arrive at, and so approaches to wicked problems should be tractable ways to improve a situation rather than solve it. 
- There is no template to follow when tackling a wicked problem, although history may provide a guide. Teams that approach wicked problems must literally make things up as they go along.

- There is always more than one explanation for a wicked problem, with the appropriateness of the explanation depending greatly on the individual perspective of the designer.

- Every wicked problem is a symptom of another problem. The interconnected quality of socio-economic political systems illustrates how, for example, a change in education will cause new behavior in nutrition.

- No mitigation strategy for a wicked problem has a definitive scientific test because humans invented wicked problems and science exists to understand natural phenomena.

- Offering a "solution" to a wicked problem frequently is a "one shot" design effort because a significant intervention changes the design space enough to minimize the ability for trial and error.

- Every wicked problem is unique.

- Designers attempting to address a wicked problem must be fully responsible for their actions.

Again, it is not the purpose of this chapter to teach wicked problems, but it is important to understand the consequences of intervening in a system hosting a wicked problem. Jon Kolko [62] has written an excellent introduction with a summary available on the Stanford Social Innovation Review site. ${ }^{20}$

\subsection{Mental Models and Systems Models}

The point of systems thinking is to be able to describe the system of interest in a way that a shared mental model among all the many stakeholders can be established for productive communication. The process of building that model, systems thinking and sensemaking, are themselves productive communication efforts.

It is beyond the scope of this chapter to describe systems models. Being able to discuss a system quickly, efficiently and completely with stakeholders is important to develop courses of intervention, agreement to intervene, and deciding upon the "success" or "failure" of the intervention. ${ }^{21}$ There are three key ${ }^{22}$ ways of describing systems:

\footnotetext{
${ }^{20} \mathrm{https} / / /$ ssir.org/articles/entry/wicked_problems_problems_worth_solving

${ }^{21} \mathrm{Keep}$ in mind that with wicked problems, interventions either make things better or worse, there is no solution (success) with a wicked problem.

${ }^{22}$ There are number of other tools that are used to map out events or how things are connected. Network mapping, social network analyses, and process mapping involve a range of tools to illustrate and analyze connections between people, organizations, or processes in both qualitative and quantitative ways.
} 
- DSRP - Distinctions, Systems, Relationships, Perspectives ${ }^{23}$ [63]

- CLD - Causal Loop Diagrams ${ }^{24}$ [64]

- SD - Systems Dynamics ${ }^{25}$ [26]

Being able to take what has been learned about the system under consideration with a tangible representation that can be shared with others is critical in establishing a shared mental model as to how to engage with that system among all the stakeholders. Mental models are important as they are how we reason. From the Princeton Mental Models and Reasoning site:

The theory of mental models rests on simple principles, and it extends in a natural way to inferring probabilities, to decision making, and to recursive reasoning about other people's reasoning. We can summarize the theory in terms of its principal predictions, which have all been corroborated experimentally. According to the model theory, everyday reasoning depends on the simulation of events in mental models (e.g., [65]). The principal assumptions of the theory are:

1. Each model represents a possibility. Its structure corresponds to the structure of the world, but it has symbols for negation, probability, believability, and so on. Models that are kinematic or dynamic unfold in time to represent sequences of events.

2. Models are iconic insofar as possible, that is, their parts and relations correspond to those of the situations that they represent. They underlie visual images, but they also represent abstractions, and so they can represent the extensions of all sorts of relations. They can also be supplemented by symbolic elements to represent, for example, negation.

3. Models explain deduction, induction, and explanation. In a valid deduction, the conclusion holds for all models of the premises. In an induction, knowledge eliminates models of possibilities, and so the conclusion goes beyond the information given. In an abduction, knowledge introduces new concepts in order to yield an explanation.

4. The theory gives a 'dual process' account of reasoning. System 1 constructs initial models of premises and is restricted in computational power, i.e., it cannot carry out recursive inferences. System 2 can follow up the consequences of consequences recursively, and therefore search for counterexamples, where a counterexample is a model of the premises in which the conclusion does not hold.

5. The greater the number of alternative models needed, the harder it is: we take longer and are more likely to err, especially by overlooking a possibility. In the simulation of a sequence of events, the later in the sequence that a critical event occurs, the longer it will take us to make the inference about it.

6. The principle of truth: mental models represent only what is true, and accordingly they predict the occurrence of systematic and compelling fallacies if inferences depend on what is false. An analogous principle applies to the representation of what is possible

\footnotetext{
${ }^{23}$ An excellent free interactive instruction on DSRP using the Plectica tool is available here: https:// cabrera-research-lab.tahoe.appsembler.com/

${ }^{24}$ An excellent introduction to Causal Loop Diagrams is available on the Systems and Us website at https://systemsandus.com/2012/08/15/learn-to-read-clds/

${ }^{25} \mathrm{An}$ absolutely amazing, comprehensive and easy introduction to systems dynamic modeling (and other forms) is available from an open source free model simulation tool Insight Maker (https:// insightmaker.com/) whose tutorials explain the different modeling approaches very well. An accompanying ebook is available (http://beyondconnectingthedots.com/). Another gentle interactive introduction to systems dynamics is available here: https://kumu.io/stw/insight-maker using the mental modeling tool kumu https://kumu.io/
} 
rather than impossible, to what is permissible rather than impermissible, and to other similar contrasts.

7. The meanings of terms such as 'if' can be modulated by content and knowledge. For example, our geographical knowledge modulates the disjunction: Jay is in Stockholm or he is in Sweden. Unlike most disjunctions, this one yields a definite conclusion: Jay is in Sweden.

The theory accounts for the informality of arguments in science and daily life, whereas logic is notoriously of little help in analyzing them.

Shared mental models are critical for collaboration and agreement before intervening in a system.

There are two models that an innovation in Health Security always needs to be cognizant of: The systems model that describes the wicked problem being addressed so that interventions can be designed, executed and monitored; the systems that describe the enterprise as discussed above in Forms of Innovation so that you understand how the two systems (and a larger system they are both part of) will interact.

One last point about adopting a systems thinking approach and using systems and mental models for innovation is the ability to leverage systems archetypes [66]. Sometimes also called design patterns, systems archetypes provide building blocks for your models based upon commonly found structures in systems. A systems archetype is a well-defined structure, exhibits a distinct behavior over time, frequently occurs across multiple disciplines of science and has well defined strategies for dealing with the implications of the structure. There are 15 (12 negative, 3 positive) reoccurring archetypes common to human systems such as Health Security. They are:

- Limits to growth

- Tragedy of the commons

- Escalation

- Eroding goals

- Addiction

- Seeking the wrong goal

- Exponential successful

- Race to the bottom

- Rule breaking

- Shifting the burden

- Fixes that fix back

- Growth Paradox

And:

- Intensity to action

- Regenerative relationships

- Status quo disruption 
There is an excellent series on systems thinking by Leyla Acaroglu on Systems Thinkers in her Disruptive Design ${ }^{26}$ blogs. These 15 archetypes are described in one. ${ }^{27}$ Gene Bellinger has developed individual short videos that explain these and many more archetypes that are available on YouTube. ${ }^{28}$

These models become the testbed for using the different types of innovation described in the Forms of Innovation section. They also provide the framework for applying Meadows' 12 points of Intervention shown in Fig. 2 and discussed in her book [26] which she later expanded upon [67] (Fig. 10b).

\subsection{Care in Intervention}

The three biggest issues in addressing wicked problems are unintended consequences, side effects and mismeasurements.

Mismeasurement, either measuring wrongly or measuring the wrong thing is the easiest to control. Before intervening in a system several measurement caveats should be kept in mind:

- Goodhart's Law ${ }^{29}$ - "When a measure becomes a target, it ceases to be a good measure." In other words, when we set one specific goal, people will tend to optimize for that objective regardless of the consequences.

- McNamara's Fallacy ${ }^{30}$ - The first step is to measure whatever can be easily measured. The second step is to disregard that which can't be easily measured or to give it an arbitrary quantitative value. The third step is to presume that what can't be measured easily really isn't important. The fourth step is to say that what can't be easily measured really doesn't exist. In other words, in pursuit of an easy measurement, context and complexity are lost.

- The Flaw of Averages [68] - plans based on average assumptions are wrong, on average.

- Pursuit of Statistical Significance [69] - statistical significance should not be equated with substantive real world significance and that empirical researchers should convey more information about the magnitude of relationships and effects. $^{31}$

\footnotetext{
${ }^{26} \mathrm{https}: / /$ medium.com/disruptive-design

${ }^{27} \mathrm{https}: / /$ medium.com/disruptive-design/tools-for-systems-thinkers-the-12-recurring-systemsarchetypes-2e2c8ae8fc99

${ }^{28} \mathrm{https} / / / \mathrm{www} . y o u t u b e . c o m /$ user/systemswiki/search?query=archetype Gene is also a major contributor to the Insight Maker project.

${ }^{29} \mathrm{https} / / /$ towardsdatascience.com/unintended-consequences-and-goodharts-law-68d60a94705c

${ }^{30} \mathrm{https} / / /$ www.logicallyfallacious.com/tools/lp/Bo/LogicalFallacies/237/McNamara-Fallacy

${ }^{31}$ This is an area where a good systems model can prevent mistakes
} 
Fig. 10b Adapted from https://thesystemsthinker. com/wp-content/uploads/ pdfs/240111pk.pdf

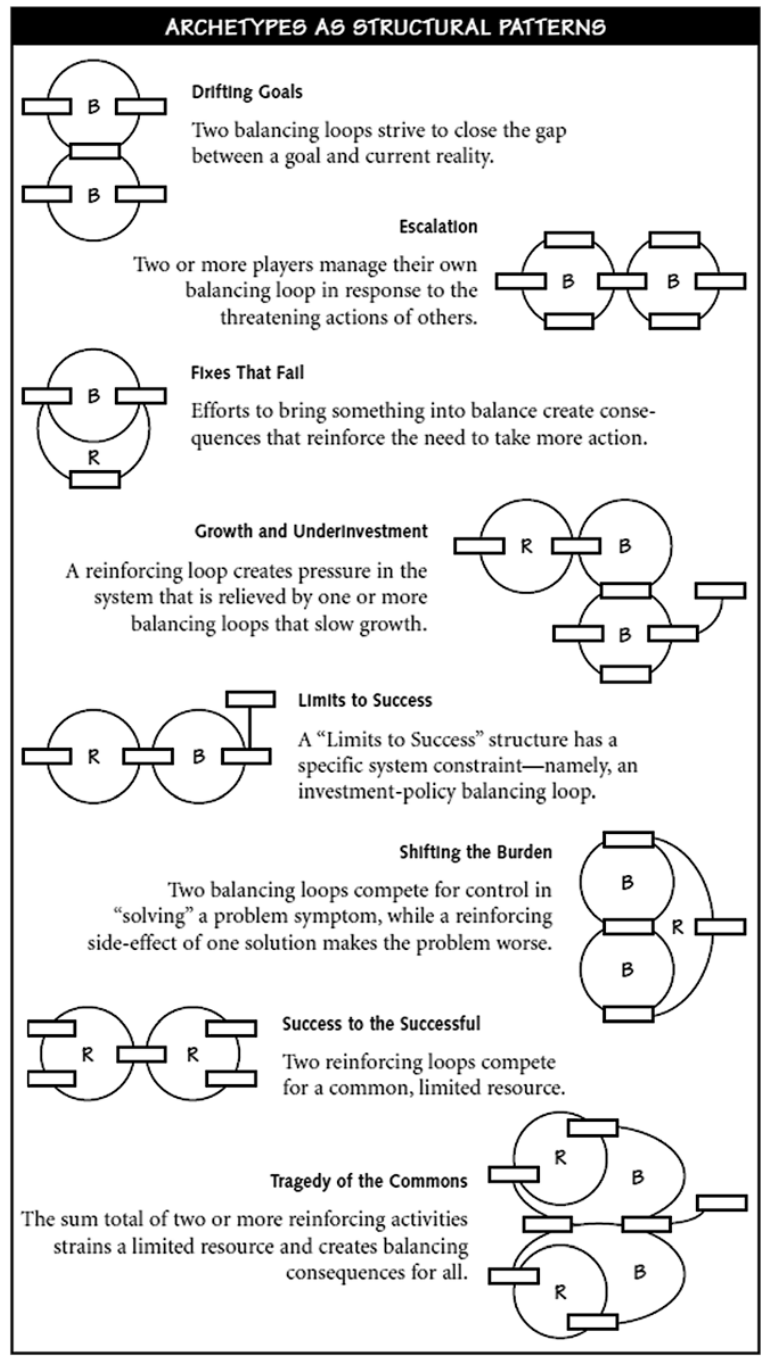

- Survivorship Bias - when failure becomes invisible, the difference between failure and success may also become invisible. This leads to assuming you should focus on the successful if you wish to become successful.

One of the key reasons for modeling systems before intervening in them is to be able to see all the interrelationships of the components of the system, and the system's relationships with other systems. One characteristic of wicked systems is their complexity and a small change in one part of the system may cause massive 
changes in another (sometimes called a butterfly effect ${ }^{32}$ [70]). These become unintended consequences.

Also, by having a systems model (shared mental model) it becomes possible to anticipate potential propagation of effects across the system anticipating side effects.

Lastly, there is a tendency when intervening in a system to do so in a way that makes it more efficient. This sometimes has an inverse effect on the efficacy of the system. More importantly, efficiency tends to reduce the resilience of a system to respond to unanticipated demands. This has been described by Taleb Nassim [71].

\section{Applying Innovation to Health Security}

\subsection{Build Shared Systems and Mental Models}

We talk about having everyone on the same page, and the best way to do that is literally. Putting a model that everyone can agree to or at least discuss ensures that when interventions take place, everyone will know what to do and why to do it.

When you have that great idea for improving things (remember one never solves wicked problems) a systems model lets you see what its potential is, both for making things better or worse. A systems model will also help identify all the interrelationships from which unintended consequences and unintended degrees of side effects occur.

The systems models will help align the enterprise (the value creation system) with its "customers" (the value consuming system) within the context of their shared environment (the systems of all stakeholders).

Begin to have meetings around diagrams, models, pictures instead of reports and spreadsheets. Have people draw their ideas in context of the system/problem being addressed. The Systems Thinker site has a good series of articles ${ }^{33}$ on how to get your organization to adopt systems thinking.

This addresses the need to have a common language of innovation as discussed earlier.

There are many ways to develop Systems Thinking within the organization. There are numerous courses online, the ones at Complexity Labs are good starting points. There are also numerous sites, Systems Thinker and Systems \& Us are two examples, with loads of material. The Waters Foundation provides a number of courses, materials and step by step guides to systems thinking. The Fifth Discipline and the associated Field Guide also provide good starting points.

\footnotetext{
${ }^{32} \mathrm{https} / / /$ www.wisegeek.com/what-is-the-butterfly-effect.htm

${ }^{33} \mathrm{https} / / /$ thesystemsthinker.com/introducing-systems-thinking-into-your-organization/
} 


\subsection{Convergent and Divergent Thinking and People}

As managers we are the masters of convergent thinking. We are analytical and rational. We are quantitively evaluative and focused, so we address one thing at a time. We work within our perceived constraints to achieve our perceived objectives. We are successful because we pay attention to specifics and their details. And our organizations reflection ourselves.

A great deal of value, especially efficiency emerges from this mode of focused convergent thinking. But when one is deep in the examination of a bark beetle in the bark of a pine tree, one likely misses the other trees, plants, animals, geology, weather - the elements of the ecosystem - that enables for that beetle to be there. That is the value of systems thinking.

Systems thinking is divergent. It is creative (because except for simple systems it is impossible to enumerate every element and every relationship, and each element and relationship can be its own system). It is intuitive, qualitative, subjective and speculative about all the possibilities that could emerge as the system pursues its purpose. Systems thinking is holistic and deals with conceptual abstractions as much if not more than specific details, because a complex system is forever displaying emergent behavior.

Divergent thinking requires divergent people (more points of view) and creativity. There are many ways to acquire and develop those people.

Meet People's Needs. Recognize that questioning orthodoxy and convention the key to creativity - begins with questioning the way people are expected to work. How well are their core needs — physical, emotional, mental, and spiritual — being met in the workplace? The more people are preoccupied by unmet needs, the less energy and engagement they bring to their work. Begin by asking employees, one at a time, what they need to perform at their best. Next, define what success looks like and hold people accountable to specific metrics, but as much as possible, let them design their days as they see fit to achieve those outcomes.

Teach Creativity Systematically. It isn't magical and it can be developed. There are five well-defined, widely accepted stages of creative thinking: first insight, saturation, incubation, illumination, and verification. They don't always unfold predictably, but they do provide a roadmap for enlisting the whole brain, moving back and forth between analytic, deductive left hemisphere thinking, and more pattern-seeking, big-picture, right hemisphere thinking. The best description of the stages I've come across is in Betty Edward's book Drawing on the Artist Within. The best understanding of the role of the right hemisphere, and how to cultivate it, is in Edwards' first book, Drawing on the Right Side of the Brain.

Nurture Passion. The quickest way to kill creativity is to put people in roles that don't excite their imagination. This begins at an early age. Kids who are encouraged to follow their passion develop better discipline, deeper knowledge, and are more persevering and more resilient in the face of setbacks. Look for small ways to give employees, at every level, the opportunity and encouragement to follow their interests and express their unique talents. 
Make the Work Matter. Human beings are meaning-making animals. Money pays the bills but it's a thin source of meaning. We feel better about ourselves when we we're making a positive contribution to something beyond ourselves. To feel truly motivated, we have to believe what we're doing really matters. When leaders can define a compelling mission that transcends each individual's self-interest, it's a source of fuel not just for higher performance, but also for thinking more creatively about how to overcome obstacles and generate new solutions.

Provide the Time. Creative thinking requires relatively open-ended, uninterrupted time, free of pressure for immediate answers and instant solutions. Time is a scarce, overburdened commodity in organizations that live by the ethic of "more, bigger, faster." Ironically, the best way to insure that innovation gets attention is to schedule sacrosanct time for it, on a regular basis.

Value Renewal. Human beings are not meant to operate continuously the way computers do. We're designed to expend energy for relatively short periods of time - no more than $90 \mathrm{~min}$ - and then recover. The third stage of the creative process, incubation, occurs when we step away from a problem we're trying to solve and let our unconscious work on it. It's effective to go on a walk, or listen to music, or quiet the mind by meditating, or even take a drive. Movement - especially exercise that raises the heart rate - is another powerful way to induce the sort of shift in consciousness in which creative breakthroughs spontaneously arise.

\subsection{Fail Fast, Fail Furiously, Learn, Try Again}

When putting together your system interventions, go small. When dealing with a complex system, the guidelines of the Cynefin Framework are to "probe", what we earlier called an hypothesis test, then sensemake from the behavior the system demonstrates in response, then respond by adjusting your hypothesis (probe) and do it over and over again until you see the improvement in the system you seek.

Large, analysis driven, too big to fail projects will fail for all the reasons discussed about taking care in intervening in a system.

\subsection{Synthesis Based Decision Making}

The fallacy of evidence-based decision making is that you really have all the evidence needed when making the decision. You may have fallen victim to either Goodhart or McNamara. The evidence may get tweaked and tuned (drop the outliers) to improve the stats, when the reality is insight and discovery often lies with the outliers. Simple unintentional color selection in data representation can skew 

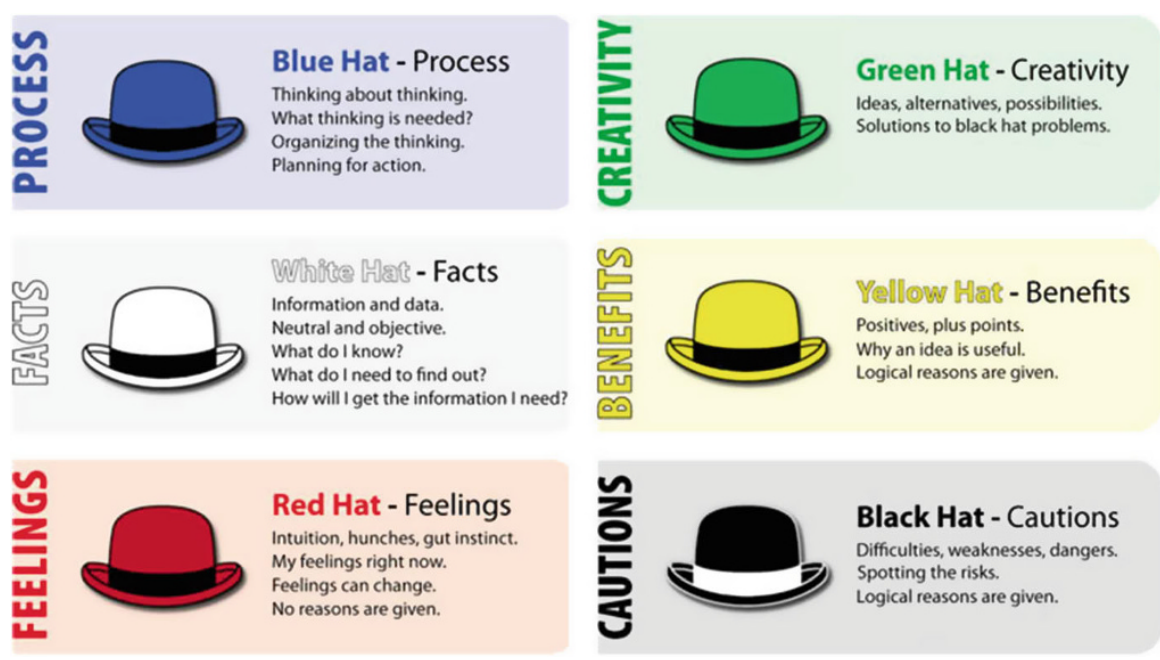

Fig. 11 Adapted from Edward De Bono's six thinking hats [74, 75]

perception. Information separated by pages or even fonts and font sizes can misrepresent relationships ${ }^{34}$ [72].

Developing a process to support synthesis-based decision making helps innovation emerge in an enterprise. One example of this is the process developed by Edward De Bono [74, 75] called the "six thinking hats". There are six metaphorical hats and each defines a certain type of thinking. By going through all six forms of thinking a team synthesizes across all the dimensions of the decision to be made including knowns (simple system elements), ${ }^{35}$ known unknowns (complicated system elements), unknown unknowns (complex system elements), and unknowables (chaotic system elements) (Fig. 11).

As described earlier, Heyman et al. [3:1888] argues that, "the world is ill-prepared" to handle any "sustained and threatening public-health emergency". The Global Health Security landscape is characterized by its inherent VUCA (volatility, uncertainty, complexity and ambiguity). These features along with the impacts of diseases globally make the requirement for innovation all the more urgent. Working across the innovation space pertaining to global health security means drawing upon the tools and approaches resident within the innovation thought leadership space. This chapter introduces the salient innovation approaches and mindset required to address Global Health Security issues.

\footnotetext{
${ }^{34}$ Sometimes with deadly consequences as Edward Tufte [73] concluded as part of the Challenger Space Shuttle accident investigation.

${ }^{35}$ Parentheticals are from the Cynefin Framework
} 


\section{Conclusion}

H1N1, SARS, H5N1, HIV/AIDS and Ebola are part of a long list of emerging lethal diseases that comprise and challenge the notion of global health security. These will not be the last new and lethal pathogen to emerge. Black swans and perfect storms are inevitable. The question arises: are we ready?

This chapter explored the foundations of the innovation space as it applies to global health security. The wicked nature of global health security points to how innovation and complexity framing go hand in hand in dealing with such global issues.

\section{References}

1. Weick KE, Sutcliffe KM (2007) Managing the unexpected: resilient performance in an age of uncertainty second edition. Wiley, California

2. Morens DM, Fauci AS (2013) Emerging infectious diseases: threats to human health and global stability. PLoS Pathog 9(7):1-3

3. Heyman et al (2015) Global health security: the wider lessons from the west African Ebola virus disease epidemic. Vol 385 May 9, 2015 www.thelancet.com

4. Rittel HWJ, Webber MM (1973) Dilemmas in a general theory of planning. Policy Sci 4(2):155

5. Masys AJ (2016) Disaster forensics: understanding root cause and complex causality. Springer Publishing

6. Helbing D (2013) Globally networked risks and how to respond. Nature 497:51-59

7. World Economic Forum Global Risks (2018) https://www.weforum.org/reports/the-globalrisks-report-2018

8. Masys AJ, Ray-Bennett N, Shiroshita H, Jackson P (2014) High impact/low frequency extreme events: enabling reflection and resilience in a hyper-connected World. 4th International Conference on Building Resilience, Building Resilience 2014, 8-10 September 2014, Salford Quays, United kingdom. Procedia Economics and Finance 18 (2014) 772-779

9. Woods DD (2006) Essential characteristics of resilience. In: Hollnagel E, Woods DD, Leveson $\mathrm{N}$ (eds) Resilience engineering: concepts and precepts. Ashgate Publishing, Aldershot, Hampshire, pp 21-34

10. Sagan SD (1993) The limits of safety organizations, accidents, and nuclear weapons. Princeton University Press

11. Belay ED, Kile JC, Hall AJ, Barton-Behravesh C, Parsons MB, Sayler S, Walker H (2017) Zoonotic disease programs for enhancing global health security emerging infectious diseases $\bullet$ www.cdc.gov/eid • vol. 23, Supplement to December 2017

12. Kickbusch I (2016) Governing the global health security domain. Global Health Programme Working paper No. 12. Graduate Institute of International and Development Studies

13. Moore M, Westley F (2011) Surmountable chasms: networks and social innovation for resilient systems. Ecol Soc 16(1):5

14. Masys AJ (2014) Disaster Management: Enabling Resilience. Springer Publishing

15. Masys AJ (2015) Applications of systems thinking and soft operations research in managing complexity. Springer

16. Masys AJ (ed) (2018) Security by design. Springer

17. Senge PM (1990) The fifth discipline: the art and practice of the learning organization. Century Business, London 
18. Westley F, Zimmerman B, Patton M (2007) Getting to maybe: how the world is changed. Random House of Canada, Toronto

19. Kurtz CF, Snowden DJ (2003) The new dynamics of strategy: sense-making in a complex and complicated world. IBM Syst J 42(3):462-483

20. Snowden D (2003) Complex knowledge. Building the knowledge economy: issues, applications, case studies, 805

21. Snowden DJ, Boone ME (2007) A leader's framework for decision making (cover story). Harv Bus Rev 85(11):68-76

22. Gallie WB (1955) Essentially contested concepts. Paper presented at the Proceedings of the Aristotelian society

23. Freeman RE, Harrison JS, Wicks AC, Parmar BL, De Colle S (2010) Stakeholder theory: the state of the art. Cambridge University Press

24. Miles S (2015) Stakeholder theory classification: a theoretical and empirical evaluation of definitions. J Bus Ethics. https://doi.org/10.1007/s10551-015-2741-y

25. Rogers EM (2010) Diffusion of innovations. Simon and Schuster

26. Meadows DH, Wright D (2009) Thinking in systems. [electronic resource]: a primer. Earthscan., 2009, London, p c2008

27. Meadows DH (2008) Thinking in systems: a primer. Chelsea green publishing

28. Meadows D (1999) Leverage points. Places to intervene in a system

29. Porter ME (1996) What is strategy. Published November

30. Birkinshaw J, Goddard J (2009) What is your management model? 81

31. Hamel G (2006) The why, what, and how of management innovation 72

32. Robertson BJ (2015) Holacracy: the new management system for a rapidly changing world. Henry Holt and Company

33. Mason-Jones R, Naylor B, Towill DR (2000) Lean, agile or leagile? Matching your supply chain to the marketplace. Int J Prod Res 38(17):4061-4070

34. Gilson LL, Maynard MT, Jones Young NC, Vartiainen M, Hakonen M (2015) Virtual teams research: 10 years, 10 themes, and 10 opportunities. J Manag 41(5):1313-1337

35. Osterwalder A, Pigneur Y (2010) Business model generation: a handbook for visionaries, game changers, and challengers. Wiley, New Jersey

36. Anthony SD (2017) The little black book of innovation, with a new preface: how it works, how to do it. Harvard Business Review Press

37. Berkhout F, Green K (2002) Managing innovation for sustainability: the challenge of integration and scale. Int J Innov Manag 6(03):227-232

38. Lafley AG, Charan R (2010) The game changer: how every leader can drive everyday innovation. Profile Books

39. Pink DH (2011) Drive: the surprising truth about what motivates us. Penguin

40. Schön DA (1983) The reflective practitioner: how professionals think in action. Ashgate Publishing Ltd, London

41. Amara R (1981) The futures field: searching for definitions and boundaries. Futurist 15(1):25-29

42. Henchey N (1978) Making sense of futures studies. Alternatives (7):24-29

43. Voros J (2003) A generic foresight process framework. Foresight 5(3):10-21

44. Taleb NN (2007) The black swan: the impact of the highly improbable (vol. 2). Random house

45. Hancock T, Bezold C (1994) Possible futures, preferable futures. Healthc Forum J 37(2):23-29

46. Bausch KC (2001) The emerging consensus in social systems theory. Kluwer Academic/ Plenum Publishers, New York, p c2001

47. Porter ME, Kramer MR (2011) Creating shared value. Harv Bus Rev 89(1/2):62-77

48. Robson R (2015) A new look at benefit corporations: game theory and game changer. Am Bus Law J 52(3):501-555. https://doi.org/10.1111/ablj.12051

49. Hines A, Bishop PJ (2006) Thinking about the future: guidelines for strategic foresight. Social Technologies, Washington, DC

50. Iveroth E, Hallencreutz J (2015) Effective organizational change: leading through sensemaking. Routledge 
Make the Work Matter. Human beings are meaning-making animals. Money pays the bills but it's a thin source of meaning. We feel better about ourselves when we we're making a positive contribution to something beyond ourselves. To feel truly motivated, we have to believe what we're doing really matters. When leaders can define a compelling mission that transcends each individual's self-interest, it's a source of fuel not just for higher performance, but also for thinking more creatively about how to overcome obstacles and generate new solutions.

Provide the Time. Creative thinking requires relatively open-ended, uninterrupted time, free of pressure for immediate answers and instant solutions. Time is a scarce, overburdened commodity in organizations that live by the ethic of "more, bigger, faster." Ironically, the best way to insure that innovation gets attention is to schedule sacrosanct time for it, on a regular basis.

Value Renewal. Human beings are not meant to operate continuously the way computers do. We're designed to expend energy for relatively short periods of time - no more than $90 \mathrm{~min}$ - and then recover. The third stage of the creative process, incubation, occurs when we step away from a problem we're trying to solve and let our unconscious work on it. It's effective to go on a walk, or listen to music, or quiet the mind by meditating, or even take a drive. Movement - especially exercise that raises the heart rate - is another powerful way to induce the sort of shift in consciousness in which creative breakthroughs spontaneously arise.

\subsection{Fail Fast, Fail Furiously, Learn, Try Again}

When putting together your system interventions, go small. When dealing with a complex system, the guidelines of the Cynefin Framework are to "probe", what we earlier called an hypothesis test, then sensemake from the behavior the system demonstrates in response, then respond by adjusting your hypothesis (probe) and do it over and over again until you see the improvement in the system you seek.

Large, analysis driven, too big to fail projects will fail for all the reasons discussed about taking care in intervening in a system.

\subsection{Synthesis Based Decision Making}

The fallacy of evidence-based decision making is that you really have all the evidence needed when making the decision. You may have fallen victim to either Goodhart or McNamara. The evidence may get tweaked and tuned (drop the outliers) to improve the stats, when the reality is insight and discovery often lies with the outliers. Simple unintentional color selection in data representation can skew 